\title{
Generation of the Ares I-X Flight Test Vehicle Aerodynamic Data Book and Comparison To Flight
}

\author{
Steven X. S. Bauer ${ }^{1}$, Steven E. Krist ${ }^{2}$ and William B. Compton ${ }^{3}$ \\ NASA Langley Research Center, Hampton, VA, 23681-2199
}

\begin{abstract}
A 3.5-year effort to characterize the aerodynamic behavior of the Ares I-X Flight Test Vehicle (AIX FTV) is described in this paper. The AIX FTV was designed to be representative of the Ares I Crew Launch Vehicle (CLV). While there are several differences in the outer mold line from the current revision of the CLV, the overall length, mass distribution, and flight systems of the two vehicles are very similar. This paper briefly touches on each of the aerodynamic databases developed in the program, describing the methodology employed, experimental and computational contributions to the generation of the databases, and how well the databases and underlying computations compare to actual flight test results.
\end{abstract}

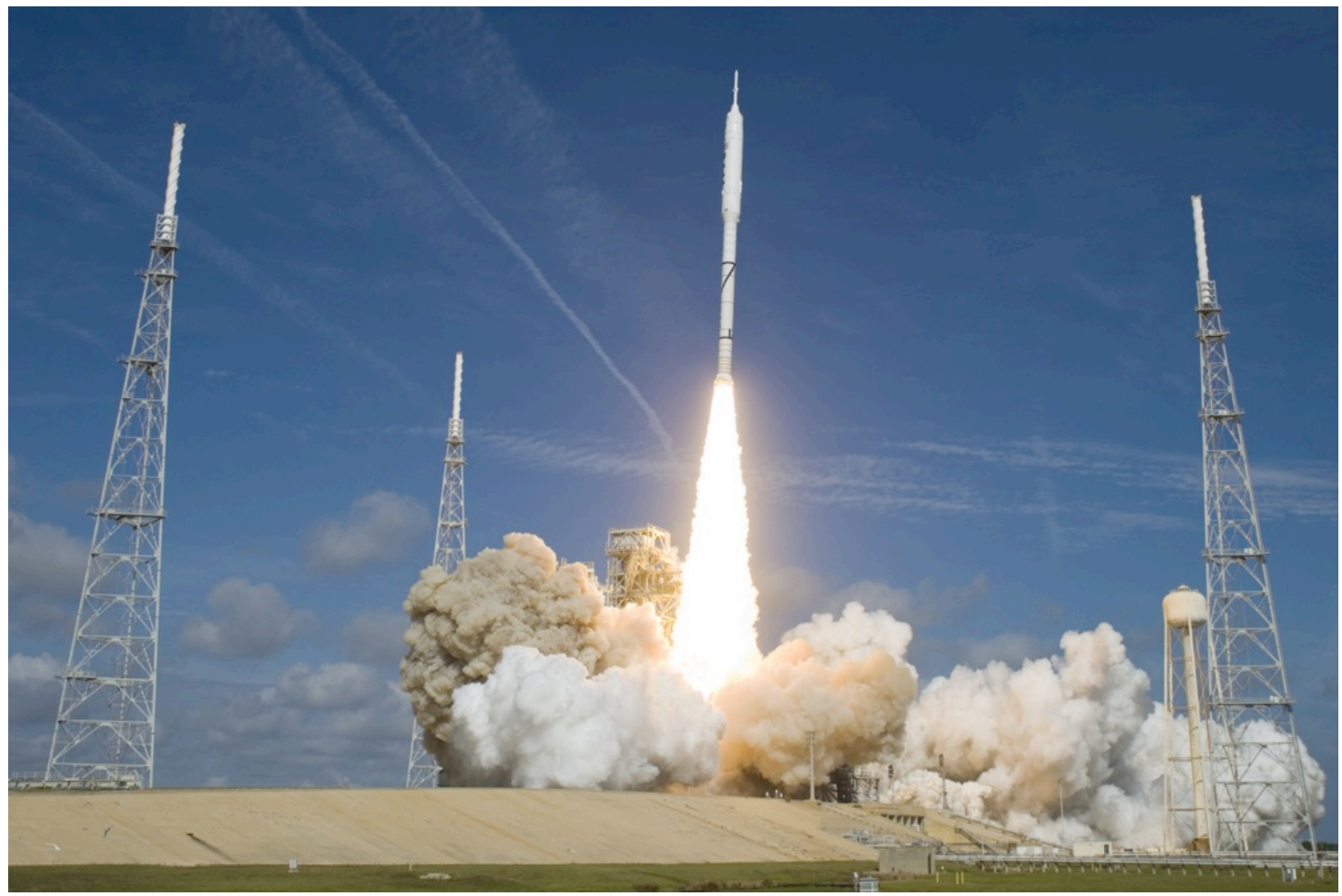

\footnotetext{
${ }^{1}$ Ares I-X Lead Aerodynamicist, NASA Langley Research Center, Hampton, VA, Configuration Aerodynamics Branch, Mail Stop 499 and AIAA Associate Fellow.

${ }^{2}$ Aerospace Engineer, NASA Langley Research Center, Hampton, VA, Configuration Aerodynamics Branch, Mail Stop 499 and AIAA Senior Member.

3 Aerospace Engineer, NASA Langley Research Center, Hampton, VA, Configuration Aerodynamics Branch, Mail Stop 499, and AIAA Senior Member.
} 


\section{Nomenclature}

\begin{tabular}{|c|c|c|c|}
\hline \multirow{3}{*}{$\begin{array}{l}A D A C \\
A E D C\end{array}$} & $=$ Ares I Design and Analysis Cycle & $N-S$ & $=$ Navier-Stokes \\
\hline & $=$ Arnold Engineering and Development & OFI & $=$ Operational Flight Instrumentation \\
\hline & Center & $O M L$ & $=$ Outer Mold Line \\
\hline \multirow[t]{2}{*}{$A P A S$} & $=$ Aerodynamic Preliminary Analysis & $P S W T$ & $=$ Polysonic Wind Tunnel \\
\hline & System & $R M$ & $=$ Rolling Moment $(\mathrm{ft} \bullet \mathrm{lbf})$ \\
\hline$A P U$ & $=$ Auxiliary Power Unit & RoCS & $=$ Roll Control System \\
\hline$A R F$ & $=$ Aerodynamic Research Facility & $R S R M$ & $=$ Reusable Solid Rocket Motor \\
\hline$B D M$ & $=$ Booster Decelerator Motor & $S A$ & $=$ Spacecraft Adapter \\
\hline$B E T$ & $=$ Best Estimated Trajectory & $S A$ & $=$ Spalart-Almaris Turbulence Model \\
\hline$B S M$ & $=$ Booster Separation Motor & $S M$ & $=$ Service Module \\
\hline BTM & $=$ Booster Tumbling Motor & SST & $=$ Menter's Shear Stress Transport \\
\hline$C F D$ & $=$ Computational Fluid Dynamics & & Turbulence Model \\
\hline$C G$ & $=$ Center of Gravity & STS & $=$ Space Transportation System \\
\hline$C_{A F}$ & $=$ Axial Force Coefficient & $T V C$ & $=$ Thrust Vector Control \\
\hline$C_{i}$ & $=$ Force and Moment Coefficients & $U P W T$ & $=$ Unitary Plan Wind Tunnel \\
\hline CEV & $=$ Crew Exploration Vehicle & $U S$ & $=$ Upper Stage \\
\hline$C L V$ & $=$ Crew Launch Vehicle & USM3D & $=$ Unstructured Mesh 3-Dimensional \\
\hline$C M$ & $=$ Crew Module & & Euler and Navier-Stokes Solver \\
\hline$C M / L A S$ & $=$ Crew Module $/$ Launch Abort System & USS & $=$ Upper Stage Simulator \\
\hline$C_{N F}$ & $=$ Normal Force Coefficient & $V A B$ & $=$ Vehicle Assembly Meeting \\
\hline$C_{P}$ & $=$ Surface Pressure Coefficient & $V K F$ & $=$ Von Karman Facility \\
\hline$C_{P M}$ & $=$ Pitching Moment Coefficient & $X$ & $=$ Axial Location (inches) \\
\hline$C_{R M}$ & $=$ Rolling Moment Coefficient & $X_{\text {rel }}$ & $=$ Relative Axial-Separation Distance \\
\hline$C_{S F}$ & $=$ Side Force Coefficient & & between USS and FS CGs (FS \\
\hline$C C W$ & $=$ Counterclockwise & & Diameters) \\
\hline CTS & $=$ Captive Trajectory System & $X_{\text {sep }}$ & $=$ Axial-Separation Distance between \\
\hline$C W$ & $=$ Clockwise & & USS and FS CGs (FS Diameters) \\
\hline$C_{Y M}$ & $=$ Yawing Moment Coefficient & $Y_{\text {sep }}$ & $=$ Lateral-Separation Distance between \\
\hline$D O F$ & $=$ Degree of Freedom & & USS and FS CGs (FS Diameters) \\
\hline$D F I$ & $=$ Developmental Flight Instrumentation & $Z_{\text {rel }}$ & $=$ Relative Vertical-Separation Distance \\
\hline ESDU & $=$ Engineering Sciences Data Unit & & between USS and FS CGs (FS \\
\hline$F \& M$ & $=$ Force and Moment & & Diameters) \\
\hline$F S$ & $=$ First Stage & $Z_{\text {sep }}$ & $=$ Vertical-Separation Distance between \\
\hline FTV & $=$ Flight Test Vehicle & & USS and FS CGs (FS Diameters) \\
\hline$G N \& C$ & $=$ Guidance Navigation and Control & $\alpha_{T}$ & $=$ Total Angle of Attack (deg) \\
\hline IS & $=$ Interstage & $\alpha$ & $=$ Angle of Attack (deg) \\
\hline$J I$ & $=$ Jet Interaction & $\beta$ & $=$ Sideslip Angle (deg) \\
\hline$K S C$ & $=$ Kennedy Space Center & $\Delta \alpha$ & $=$ Difference in Angle of Attack between \\
\hline LaRC & $=$ Langley Research Center & & USS and FS (deg) \\
\hline$L A S$ & $=$ Launch Abort System & $\Delta \beta$ & $=$ Difference in Sideslip Angle between \\
\hline$L S C$ & $=$ Linear Shape Charge & & USS and FS (deg) \\
\hline$L V$ & $=$ Launch Vehicle & $\Delta C_{i}$ & $=$ Change in Force and \\
\hline$M L O A$ & $=\begin{array}{l}\text { Merged Liftoff, Ascent, High-Angle- } \\
\text { of-Attack }\end{array}$ & & Coefficient \\
\hline & $=$ Mobile Launch Platform & $\phi$ & $=$ Roll Angle $(\mathrm{deg})$ \\
\hline$M S F C$ & $=$ Marshall Space Flight Center & $\Phi$ & $=$ Azimuth Angle (deg) \\
\hline
\end{tabular}

\section{Introduction}

$\mathrm{T}$

HE purpose of this document is to present the methodology employed in generating the aerodynamic databases for the Ares I-X Flight Test Vehicle (FTV). This document briefly describes the development of the Ares I-X FTV and the required aerodynamic and airloads databases for mission simulation and analysis. These databases provided the design data for the FTV ascent, stage separation, and reentry phases of flight. Airloads and aeroelastic databases were provided for structural analysis at all points in the nominal ascent trajectories. 
The airloads database was developed from experimental and computational results and was provided to the structural analysis team for development of the main vehicle structural design loads and bending modes. The unsteady aerodynamics and aeroelasticity data provided additional loading conditions that could be as large as those provided from steady state conditions (e.g., a bimodal event that was identified in rigid buffet testing of the FTV). The results were used to assess the structural integrity of the FTV and assisted in the proper placement of inertial measurement devices required for the flight system. In addition, pressure distributions were provided for use in the design of vehicle venting systems.

The flight of the Ares I-X FTV on October 28, 2009 was nominal, other than an issue with deployment of the FS parachutes. In addition to meeting all of the primary and secondary objectives, the flight test provided copious amounts of data that have been used to examine the veracity of pre-flight analyses in predicting the actual flight performance of the vehicle. Information from the post flight analyses were intended for use in validating and/or updating the Ares I databases and tools as required and appropriate.

\section{Background}

\section{A. Ares I Crew Launch Vehicle}

The vehicle designed to launch the Orion Crew Exploration Vehicle (CEV) was the Ares I Crew Launch Vehicle (CLV), a two-stage configuration designed to boost the Orion to orbit. Its two main propulsive elements were a reusable solid rocket motor (RSRM) first stage (FS) and a J-2X main engine second stage. The Ares I CLV was designed to be capable of inserting a 22.9-mt payload into an orbit for an International Space Station mission.

The FS was derived from the Shuttle-heritage reusable RSRM and was composed of five field-assembled segments, an aft skirt containing the thrust vector control (TVC) hydraulic system, accompanying auxiliary power units (APUs), booster deceleration motors (BDMs), and booster tumbling motors (BTMs). The aft skirt provided the structural attachment to the mobile launch platform (MLP) through four attachment points (hold-down posts) with explosive bolts. The single exhaust nozzle was semi-embedded and was movable by the TVC system to provide pitch and yaw control during ascent. A stage adapter that houses the RSRM recovery system elements and a roll control system (RoCS) replaced the Shuttle-based Space Transportation System (STS) forward skirt, frustum, and nose cap. After separation from the upper stage (US), the FS was forced into a tumble by the use of four BTMs. The FS was designed to coast upward in a ballistic arc, subsequently reentering the atmosphere and landing by parachute in the Atlantic Ocean for retrieval and reuse, similar to the current Shuttle RSRM.

\section{B. Ares I-X Flight Test Vehicle}

The Ares I-X FTV was developed to provide an early flight demonstration of the Ares I CLV concept and to provide full-scale flight data to aid in its final design. The Ares I-X FTV was an integrated, stacked vehicle that consisted of three stack elements: first stage (FS), upper stage simulator (USS), and crew module (CM)/launch abort system (LAS) simulator (CM/LAS). Additional integrated elements included the RoCS and a distributed avionics element.

The FS was identical in length to the Ares I A101 five-segment booster configuration to support the flight test objective of demonstrating descent and recovery of a spent five-segment booster. It was comprised of a foursegment Space Shuttle RSRM, an empty (no propellant) fifth segment, the forward skirt extension (containing the first stage recovery systems), the forward skirt and the frustum to carry FS loads to the interstage.

The USS was comprised of an interstage, beginning at the FS interface, and boilerplate simulators of the Ares I A101 US, the CEV, spacecraft adapter (SA), and service module (SM). These simulators were intended to match the outer mold line (OML), center of gravity (CG), and the moments of inertia of the Ares I Constellation Components. These last two elements, the SA and SM, were part of the Constellation CEV but were included as part of the USS for the Ares I-X FTV.

The CM/LAS was comprised of the CM and the launch abort tower. The OML of the CM/LAS was the same as that of the Ares I A101 (Orion 605-054) configuration. The elements of the stack are shown in figure 1. 


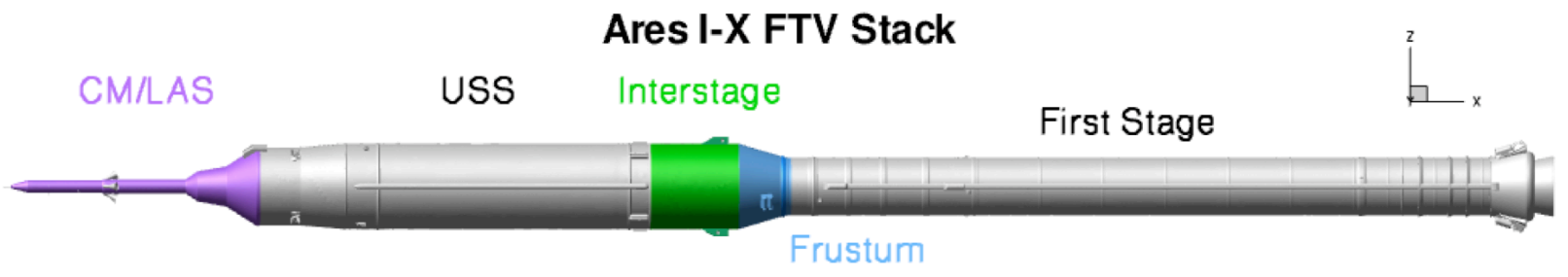

Figure 1. Elements of the Ares I-X FTV stack.

The Ares I-X FTV used an existing avionics system with flight control algorithms specific to the FTV and the CLV. The key features of the avionics were: flight control, telemetry systems, data recording, power, range safety system, imaging, electrical ground support equipment, developmental flight instrumentation (DFI), operational flight instrumentation (OFI), and flight software.

The Ares I-X FTV RoCS provided the roll control of the vehicle. The RoCS were installed on the interstage and were controlled via the system avionics package.

The Ares I-X FTV was a heavily instrumented launch vehicle. The FTV had 243 unsteady pressure (Kulite) gauges installed on the surface of the vehicle. In addition to the surface pressure measurements, the vehicle had numerous strain gauges, accelerometers, thermocouples, and other measurements to control the vehicle in flight and to determine the flow characteristics, vehicle state, and location during flight.

\section{The five primary objectives of the Ares I-X FTV were to:}

- Demonstrate control of a vehicle dynamically similar to the Ares I/Orion vehicle using the Ares I relevant flight control algorithms.

- Perform a nominal in-flight separation/staging event between an Ares I-like first stage and a representative upper stage.

- Demonstrate assembly and recovery of a new Ares I-like first stage element at Kennedy Space Center (KSC).

- Demonstrate first stage separation sequencing and quantify first stage atmospheric entry dynamics and parachute performance.

- Characterize magnitude of integrated vehicle roll torque throughout first stage flight.

The secondary objectives of the Ares I-X FTV were to:

- Quantify the effectiveness of the first stage separation motors.

- Characterize induced environments and loads on the FTV during ascent flight phases.

- Demonstrate a procedure to determine the vehicle's prelaunch geodetic orientation vector for initialization of the flight control system.

- Characterize induced loads on the LV on the launch pad.

- Assess potential Ares I access locations in the Vehicle Assembly Building (VAB) and on the pad.

- Validate first stage electrical umbilical performance.

Of the five primary flight test objectives, four were intimately involved with the characterization of the aerodynamic behavior of the vehicle. Likewise, three of the secondary objectives relied on aerodynamic assessments.

\section{Configurations}

A primary requirement of the Ares I-X FTV was to mimic as closely as possible the characteristics of the Ares I CLV. From an aerodynamics perspective, particular concern was placed on maintaining commonality in the outer mold line (OML) of the two vehicles. However, due to the need to freeze the Ares I-X OML relatively early with respect to the Ares I design process, the degree of commonality between the configurations deteriorated with each new Ares I design cycle.

The initial design of the FTV was based on the Ares I design and analysis cycle 2A (ADAC-2A) A101 configuration. Some of the more significant aspects of this configuration included locating the separation plane for the first stage separation event at the intersection of the interstage with the upper stage, locating the BDMs on the interstage and covering them with rather prominent housings, and locating the BTMs on the frustum. Subsequent Ares I design cycles moved the BDMs back onto the aft skirt of the FS and modified the forebody to utilize a SearsHaack minimum drag shape for aeroacoustic and performance reasons. 
A significant change on the FTV OML came about with the decision to move the separation plane from the top of the interstage to the bottom of the frustum. The change in separation plane had a considerable effect on the aerodynamic characteristics of the stage separation event. Modification of the separation plane made it necessary to move the BDMs and BTMs for the FTV down onto the aft skirt. Since the BTMs of the CLV were on the frustum, the OML of the FTV was further modified by placing dummy BTMs on the frustum to retain some of the commonality between the configurations.

All of the changes discussed above were embodied in the Ares I-X FTV v2.01 OML; this is the OML used for all preflight computations for which results were incorporated into the aerodynamic databases. Later OML versions include more modest revisions than discussed above, such as a change in the shape of the linear shape charge (LSC) located at the intersection of the FS with the frustum, a repositioning of the dummy BTMs on the frustum to conform to the position of the CLV BTM locations, and the incorporation of additional sensors.

A final OML was constructed after completion of the flight test. During stacking of the vehicle in the Kennedy Space Center (KSC) vehicle assembly building (VAB), a detailed scan of the OML of each component was conducted, as was a scan of the fully stacked vehicle. The scans also identified the locations of the protuberances for detection of any misalignments between the specified locations and the final positions. The cloud of points acquired from the scans was used to generate an OML definition, referred to as the "As-Built" OML.

The effect that the design changes had on processes for generating the aerodynamic databases, particularly the ascent and stage separation databases, was substantial.

\section{Aerodynamic Assessments}

The aerodynamic databases were constructed with data generated from wind tunnel experiments, computational fluid dynamics (CFD) simulations, engineering analyses, and heritage systems. A number of the databases, such as the stage separation database, were constructed entirely from wind tunnel data. Others, such as the jet interaction databases, were constructed entirely from CFD results. The majority of the databases were constructed by fusing the data from wind tunnel, CFD, and engineering analyses.

Due to the long lead times inherent in wind tunnel testing, the wind tunnel models did not conform to the FTV v2.01 OML or later OML revisions. Wind tunnel data used in constructing the ascent database was from a test of the Ares I A101 configuration. The stage separation wind tunnel tests were conducted on axisymmetric models of the FS and USS in proximity. Wind tunnel models for generating descent aerodynamic data included some of the major protuberances on the FTV, but for an OML that predates the v2.01 OML.

Most of the CFD results, and all of the CFD results presented in this paper, were obtained using the USM3D ${ }^{1,2}$ flow solver. USM3D is a tetrahedral cell-centered, finite volume method for solving the Euler and Navier-Stokes $(\mathrm{N}-\mathrm{S})$ equations. It has a variety of turbulence models for closure of the N-S equations, including the 1-equation Spalart-Almaris (SA) model and the 2-equation Menter's Shear-Stress Transport (SST) model. All computational data that was employed in generating the aerodynamic databases was obtained using the SA turbulence model. Subsequent post-flight computations were conducted with both the SA and SST models.

The features of the AIX FTV that were included in various computations depended on the type of computation required. The configuration used for computations performed in development of the ascent database, referred to as the Full Protuberance configuration, embodies most of the features of the v2.01 OML, including not just the large protuberances like the RoCS housing, but protuberances as small as the antennas and numerous stiffener rings. The two major simplifications in the CFD model were that the RoCS nozzles were faired over and a dummy sting extended out from the FS nozzle exit plane to simulate both the FS motor plume and a wind tunnel sting. The configuration used for computations performed in development of the RoCS jet interaction database was derived from the Full Protuberance configuration, but internal surfaces of the RoCS nozzles were modeled so that the firing RoCS could be simulated. Since the grid resolution requirements for modeling the jet wakes of the firing RoCS was substantially greater than that for the faired RoCS housing, the smaller protuberances and a number of the stiffener rings were removed from the CFD model in order to decrease the computational requirements. Similar simplifications were employed in modeling for the main engine, BDM, and BTM jet interaction simulations.

The sole exception to the use of USM3D in generating the CFD data to populate the databases occurred for the First Stage Wake Aerodynamics Database, which fused wind tunnel data from the stage separation test with results from the CFD-FASTRAN flow solver. Like USM3D, CFD-FASTRAN solves the Euler and full Navier-Stokes equations, with numerous options available for the turbulence model. Simulations were conducted with the FS in proximity to the USS using the SST turbulence model. 


\section{Aerodynamic Databases}

The Ares I-X Aerodynamic Data Book (AI1-SYS-ARO) contains all the reference material along with pertinent drawings for the Ares I-X FTV. The data book also contains detailed descriptions of the wind tunnel and CFD data used to develop each of the aerodynamic databases. The following sections will describe the FTV ground wind loads database; merged liftoff, ascent, and high angle of attack force and moment and lineloads databases; the stage separation database; the first stage wake database; and the first stage and upper stage reentry databases. In addition, several jet interaction databases were generated: Main Engine Plume Interaction, RoCS Jet Interaction, BDM Jet Interaction, and BTM Jet Interaction databases. Uncertainty quantification was conducted on each of the force and moment $(\mathrm{F} \& \mathrm{M})$ databases and dispersion bounds were provided to the users.

\section{A. Ground Wind Loads Database}

The ground wind loads were generated from 3 sources: (1) wind tunnel data, (2) CFD results computed at total angle of attack $\alpha_{\mathrm{T}}=90^{\circ}$, and engineering methods $\left(\mathrm{ESDU}^{3}\right)$. This database provided the force and moment values and lineloads at total angle of attack, $\alpha_{\mathrm{T}}=90^{\circ}$ for wind directions varying from $0^{\circ}$ to $360^{\circ}$ to the loads and structures team. The lineloads are the local force and moment values as a function of the running length of the vehicle. These local force and moment values were calculated by integrating the pressures on a localized area of the vehicle.

\section{B. Merged Liftoff, Ascent, and High Angle of Attack Databases}

The merged liftoff, ascent and high-angle-of-attack (MLOAHA) databases were a combination of three 6 degree of freedom (6 DOF) aerodynamic databases: (1) liftoff and transition databases, (2) ascent aerodynamic databases, and (3) malfunction turn databases. Each of these databases contained a force and moment database and an accompanying lineloads database.

The liftoff and transition database was primarily generated using CFD results at Mach 0.3 at $\alpha_{\mathrm{T}}$ values from $0^{\circ}$ to $90^{\circ}$. These CFD values were adjusted using the ground wind loads wind tunnel data at the $\alpha_{T}=90^{\circ}$ condition and engineering guidelines from the ESDU reports. The results were then converted from the missile axis to the body axis and the lineloads were adjusted so that the integrated load would match the corresponding condition in the force and moment database. Although the data was generated at a Mach number of 0.3, extrapolation is used to extend the applicability of the database to cover the Mach number range from 0 to 0.3 .

The ascent aerodynamic databases were generated using existing wind tunnel data for the Ares I A101 configuration from the Boeing Polysonic Wind Tunnel (PSWT) and the NASA Langley Research Center (LaRC) Unitary Plan Wind Tunnel (UPWT) at Mach numbers from 0.5 to 1.6 and 1.6 to 4.5 , respectively. CFD simulations were conducted at wind tunnel conditions on both the A101 and FTV configurations, thereby providing increments to the wind tunnel force and moment coefficients to account for differences in the protuberances of the two configurations. Protuberances on the two configurations are highlighted in figure 2, with differences between the two configurations shaded in magenta. Additional CFD simulations on the FTV configuration at flight Reynolds numbers were used to provide an increment between wind tunnel and flight conditions; these increments were included in the dispersions bounds on the database. The ascent aerodynamic databases cover $\alpha_{T}$ values from $0^{\circ}$ to $7^{\circ}$ and roll angles, $\phi$, from $0^{\circ}$ to $360^{\circ}$.

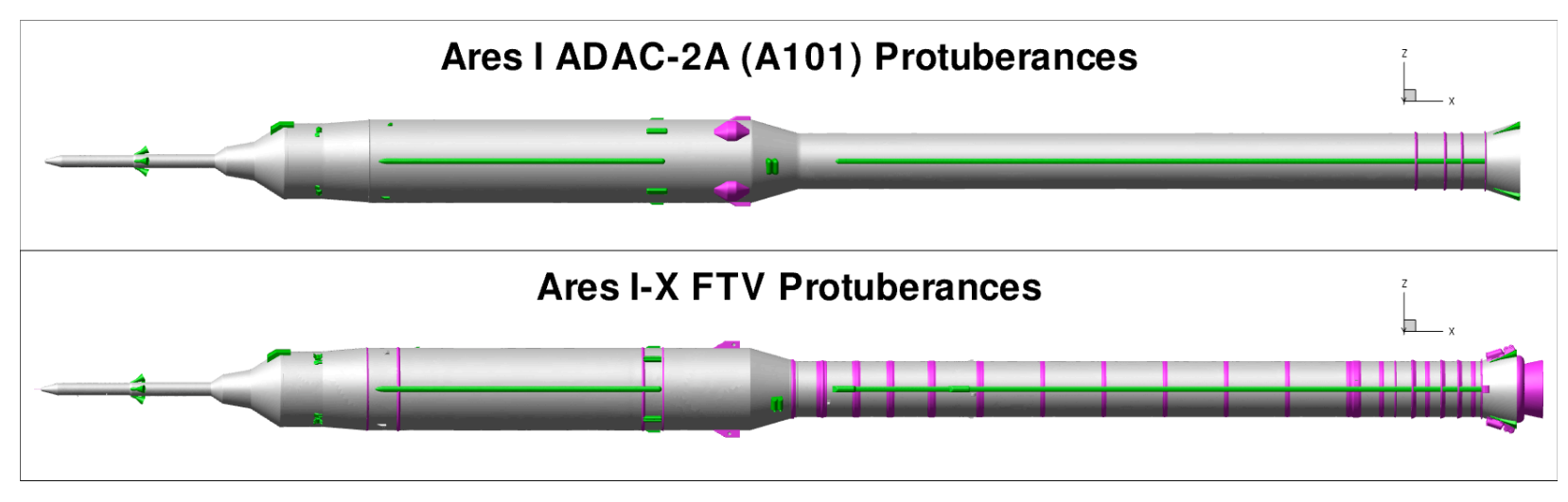

Figure 2. Protuberance differences between the Ares I ADAC-2A and Ares I-X FTV v2.01 configurations. 
The malfunction turn database was originally only a 3 DOF force and moment database. In order to merge it with the other two databases, it was updated to $6 \mathrm{DOF}$ and lineloads were generated at each $\alpha_{\mathrm{T}}$ and $\phi$ value. The malfunction turn database covered the Mach range from 0.5 to 4.5 for $\alpha_{T}$ values from $10^{\circ}$ to $90^{\circ}$. The data for this database came directly from CFD simulations conducted on the Full Protuberance configuration.

The MLOAHA databases (force and moment and lineloads) are square databases that cover the Mach range from 0 to $4.5, \alpha_{\mathrm{T}}$ from $0^{\circ}$ to $90^{\circ}$ and $\phi$ from $0^{\circ}$ to $360^{\circ}$. These 2 databases allowed the users (guidance, navigation and control [GN\&C], trajectory, and loads groups) to simulate the characteristics of the FTV by flying trajectories through one set of databases that cover all possible velocities and orientations of the vehicle.

The total aerodynamic coefficients $\left(\mathrm{C}_{\mathrm{i}}\right)$ consist of the baseline forebody coefficient values plus increments to account for FS motor power-on forebody, FS motor power-on base, roll control system jet interference, flexibility, and damping derivative effects. The forebody was defined as starting at the aft end of the aft skirt and extending forward to the tip of the nose. The following equation was used to generate each total aerodynamic coefficient:

$$
\mathrm{C}_{\mathrm{i}}=\mathrm{C}_{\mathrm{i}, \text { Forebody }}+\Delta \mathrm{C}_{\mathrm{i}, \text { Power-On,Forebody }}+\Delta \mathrm{C}_{\mathrm{i}, \text { Power-On,Base }}+\Delta \mathrm{C}_{\mathrm{i}, \text { RoCS }, \mathrm{Jl}}+\Delta \mathrm{C}_{\mathrm{i}, \text { Flex }}+\Delta \mathrm{C}_{\mathrm{i}, \text { Damping }}
$$

\section{Stage Separation Database}

The Ares I-X stage separation aerodynamics database accounted for the effects of proximity between the FS and USS on the force and moment coefficients during the stage separation event. The total separation force and moment coefficients for the detached segments were partitioned into two components (following the Shuttle Program convention): (1) Isolated Vehicle and (2) Proximity Effects.

Total separation force and moment coefficients were defined as:

$$
\begin{aligned}
& C_{i, \text { TotalAero,US }}=C_{i, \text { solatedVehicle,US }}+\Delta C_{i, \text { Pr oximityEffects, US }} \\
& C_{i, \text { TotalAero,FS }}=C_{i, \text { solatedVehicle,FS }}+\Delta C_{i, \text { Pr oximityEffects, FS }}
\end{aligned}
$$

where i refers to any of the six forces or moments.

The stage separation database was based on data obtained during a combined Ares I and I-X stage separation wind tunnel test carried out in the Arnold Engineering Development Center (AEDC) von Karman Facility (VKF) Tunnel A. Figure 3 shows the USS and FS models in the test section with the sidewalls removed and a rendering of the FS and the USS in the VKF Tunnel A. The USS was supported by an injection system mounted blade support that provided pitch variations via multiple dowel pin locations on the blade/injection assembly. The wind tunnel setup only allowed for positive USS angles of attack $\left(0^{\circ}, 5^{\circ}\right.$, and $\left.10^{\circ}\right)$ and no USS sideslip. The USS could be retracted from the flow into a pressurized chamber beneath the test section without having to stop the flow in the tunnel. This was practical for model configuration changes. A captive trajectory system (CTS) was used to support the sting mounted FS. With its 6 DOF movement capability, the CTS enabled a very large number of data points to be acquired in an efficient manner, which was crucial to achieving the goal of gathering a dense set of data points.
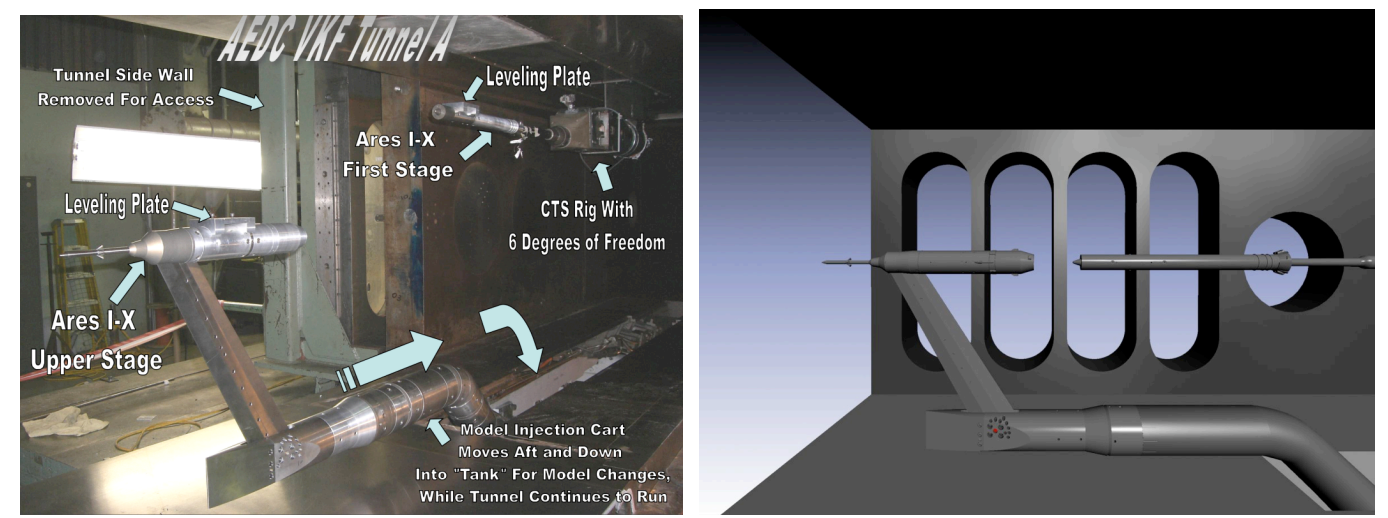

Figure 3. Ares I-X first stage (FS) and uppers stage simulator (USS) models installed in the AEDC VKF Tunnel A (left) and rendering (right).

The 6 degrees of freedom in the database are: USS angle of attack $(\alpha)$, downstream separation between the vehicles $\left(\mathrm{X}_{\text {sep }}\right)$, vertical separation $\left(\mathrm{Z}_{\text {sep }}\right)$, lateral separation $\left(\mathrm{Y}_{\text {sep }}\right)$, FS angle of attack relative to the USS $(\Delta \alpha)$ and FS sideslip angle relative to the USS $(\Delta \beta)$. All the data were acquired by sweeping the FS downstream parallel to the 
USS longitudinal axis, with the USS held in a fixed position at the center of the test section. A total of 4493 sweeps were performed (34,311 data points) during this test, with over 2000 runs for the Ares I-X configuration. The Ares I-X portion of the test was run at a Mach number of 4.5, the stage separation Mach number for the FTV.

This database provided incremental coefficients for first stage and upper stage post separation. These incremental coefficients were with respect to corresponding free stream conditions at Mach 4.5. The AEDC wind tunnel test data were obtained on clean, axisymmetric models; all effects of asymmetries as well as protuberance effects are accounted for in an uncertainty model.

\section{First Stage (FS) Wake Aerodynamics}

The FS wake database provides aerodynamic information for the first stage after the stage separation event (which concludes with the firing of the BTMs) and before reentry (with the FS approximately 100 reference diameters downstream from the USS). Driving the necessity for this database is the need to obtain initial conditions for the reentry event in order to predict the likelihood of a nose-lock orientation during reentry, in which the FS ceases tumbling and locks into an orientation with $\alpha_{T}=0^{\circ}$, plunging like a lawn dart. In the event of a nose-lock, the first stage descends at a speed that may cause the recovery parachutes to fail to open properly, leading to a destructive water impact.

This database was developed, and should be implemented, independent of the USS attitude. The wake database was presented as a 3 degree of freedom ( $3 \mathrm{DOF})$ database. Axial force coefficient $\left(\mathrm{C}_{\mathrm{AF}}\right)$, normal force coefficient $\left(\mathrm{C}_{\mathrm{NF}}\right)$, and pitching moment coefficient $\left(\mathrm{C}_{\mathrm{PM}}\right)$ were provided. However, these were to be interpreted as the forces and moments acting on the first stage within the tumbling plane defined by the first stage longitudinal axis and the upper stage center of gravity (CG). The F\&M were then projected back into any reference frame used in the simulations as the first stage tumbles and this plane rotates in the three dimensional space. This process resulted in a 6 DOF database, assuming the rolling moment coefficient $\left(\mathrm{C}_{\mathrm{RM}}\right)$ due to aerodynamic forces was zero.

The wake database was constructed by fusing part of the Ares I-X stage separation database with CFD data from the CFD-FASTRAN flow solver. The CFD dataset consists of 126 data points at angles of attack ranging from $0^{\circ}$ to $160^{\circ}$, longitudinal relative separation distances $\left(\mathrm{X}_{\mathrm{rel}}\right)$ ranging from approximately 13 to 65 reference diameters, and lateral relative separation distances $\left(Z_{\text {rel }}\right)$ ranging from -5 to 20 reference diameters, thereby covering a wide range of the first stage dispersed trajectories.

\section{E. First Stage (FS) Descent Aerodynamics Database}

The Ares I-X first stage (FS) descent aerodynamics database was based upon wind tunnel data obtained from the Marshall Space Flight Center (MSFC) 14-Inch Trisonic Wind Tunnel located at the Aerodynamic Research Facility (ARF). The test was conducted on a 0.5 percent scale model at Mach numbers from 0.5 to 4.96 and angles of attack ranging from $0^{\circ}$ to $180^{\circ}$. The same model was tested in the Boeing Polysonic Wind Tunnel at Mach numbers from 0.5 to 1.46 at angles of attack ranging from $90^{\circ}$ to $180^{\circ}$. The first-stage descent aerodynamics database relies upon direct insertion of wind tunnel test data for the normal force $\left(\mathrm{C}_{\mathrm{NF}}\right)$, pitching moment $\left(\mathrm{C}_{\mathrm{PM}}\right)$, and axial force $\left(\mathrm{C}_{\mathrm{AF}}\right)$ coefficients to populate the database matrix. While the side force $\left(\mathrm{C}_{\mathrm{SF}}\right)$, yawing moment $\left(\mathrm{C}_{\mathrm{YM}}\right)$, and rolling moment $\left(\mathrm{C}_{\mathrm{RM}}\right)$ coefficients were measured in the wind tunnel test, they were not used to create coefficient data for this database due to the force and moment measurements being on the same order as the balance uncertainty. Instead, values for these coefficients were simply carried over from the four-segment Shuttle RSRM database with no change.

In addition to the above FS descent aerodynamic database, a FS damping derivative database was generated. This database covered Mach numbers from 0.4 to 6.0 for angles of attack from $0^{\circ}$ to $180^{\circ}$ and roll angles from $0^{\circ}$ to $360^{\circ}$. This database was generated using results from the NASA/LaRC Aerodynamic Preliminary Analysis System $\left(\mathrm{APAS}^{4,5}\right.$ ). APAS consists of a suite of computer codes developed to quickly and efficiently estimate vehicle aerodynamic characteristics in the conceptual and preliminary design phases. APAS has been used to generate vehicle aerodynamic databases for conceptual design studies of one- and two-stage to orbit reusable launch vehicles, hypersonic cruise vehicles, and Hyper-X project flight test vehicles.

\section{F. Upper Stage Simulator (USS) Descent Aerodynamics Database}

The Ares I-X upper stage simulator (USS) descent aerodynamics database was based upon CFD (USM3D) results for the Ares I-X FTV at Mach numbers from 0.5 to 5.0 at angles of attack from $0^{\circ}$ to $180^{\circ}$. The database was augmented with wind tunnel data obtained from the Marshall Space Flight Center 14-Inch ARF on a 0.5 percent scale model of the A101 upper stage, including the launch abort system (LAS), at Mach numbers ranging from 2.99 to 4.96 for angles of attack ranging from $-3^{\circ}$ to $42^{\circ}$. Photographs showing the test model installed in ARF are presented in figure 4. 




Figure 4. Photographs of the Ares I A101 test model installed in the aerodynamic research facility (ARF).

The USS descent aerodynamics database was utilized after the stage separation event. The database covered Mach numbers from 0.0 to 5.0 and angles of attack from $0^{\circ}$ to $180^{\circ}$. It was a 6 DOF database, however, the rolling moment coefficient values were identically equal to zero.

In addition to the above USS descent aerodynamic database, a USS damping derivative database was generated. This database covered Mach numbers from 0.5 to 6.0 for angles of attack from $0^{\circ}$ to $180^{\circ}$ and roll angles from $0^{\circ}$ to $360^{\circ}$. This database was generated using results from the APAS.

\section{G. Additional Descent Aerodynamics Databases}

Two additional descent databases were generated entirely from CFD (USM3D). These were the AIX_USS_NoTower and AIX_LASTower descent databases. The AIX_LASTower OML included the LAS tower up to the "party hat" (the fairing between the CM and the LAS tower), while the AIX_USS_NoTower OML included the USS minus the LAS Tower. Each database was constructed from CFD runs conducted at Mach numbers ranging from 0.5 to 5.0 for angles of attack from $0^{\circ}$ to $180^{\circ}$.

\section{H. Main Engine Plume Interaction Database}

The main engine plume interaction database was generated to provide an increment to account for the effects of the powered FS motor on the forebody flow field, as the interaction effect was not accounted for in any of the other databases. CFD simulations, with both an idle and firing FS motor, were conducted at a limited number of conditions to generate 6 DOF force and moment coefficients, force coefficient line load distributions, and pressure coefficient fields on the surface of the vehicle. The 6 DOF force and moment coefficients were calculated for the full vehicle and broken down for each of 69 components. Lineloads for the axial, side, and normal force coefficient were computed at 1,000 equi-distributed points along the length of vehicle for each flow condition. Pressure coefficient values on the surface of the vehicle were computed at each flow condition and are available in a format where the aerodynamic forces for each of the 69 components can be extracted.

An example of the flowfield images generated is shown in figure 5, where results at Mach 1.4 for the idle and powered FS motor are displayed. While the powered FS motor had a large impact on the pressure field experienced by the thermal curtain and FS motor nozzle, no differences in pressure or Mach contours were evident upstream of the Aft Skirt. Lineloads also showed no differences. Since the plume interaction effects were found to be very small over the entire Mach range, increments to correct the 6 DOF MLOAHA database for RSRM main engine plume jet interaction effects were set to zero. 




Figure 5. Comparison of main engine plume IDLE (left) and ON (right) cases at Mach 1.4.

\section{RoCS Jet Interaction Database}

The Roll Control System (RoCS) used on the Ares I-X FTV is comprised of Peacekeeper missile components obtained from the United States Department of Defense, located in housings positioned on the top and bottom of the interstage (at azimuth angles of $0^{\circ}$ and $180^{\circ}$ ). Each RoCS housing contained two motors, one of which fired to induce a positive rolling moment, while the other fired to induce a negative rolling moment. Figure 6 pictorially illustrates these coupled RoCS jets firing to produce positive (clockwise, $\mathrm{CW}$, as viewed from a pilot head up orientation) and negative (counterclockwise, $\mathrm{CCW}$ ) rolling moments. While the performance parameters of the RoCS motors were supplied by NASA Marshall Space Flight Center, plume-induced interactions of the RoCS on the environment of the full stack were assessed with CFD.

The CFD simulations of RoCS jet effects employed the methodology developed by Deere, Pao, and AbdolHamid $^{6}$ for analyzing the AIX FTV RoCS installation, and applied by Deere et al. ${ }^{7}$ for analyzing the Ares I CLV RoCS installation. The ideal gas analysis of the RoCS jet effects made use of a truncated jet nozzle with the inflow plane located in supersonic flow downstream of the nozzle throat and upstream of the nozzle exit plane. Starting with the real gas thruster exit plane conditions provided by MSFC, temperature, speed of sound, and exit Mach number, for air as an ideal gas, are derived to match the real gas exit velocity. Ideal gas aerodynamic equations were then used to determine the conditions at the inflow plane. The resulting procedure was capable of matching density, pressure, velocity, mass flow rate, and thrust of the ideal gas to that of the real gas. However, temperature could not be matched and was higher for the ideal gas than for the real gas.
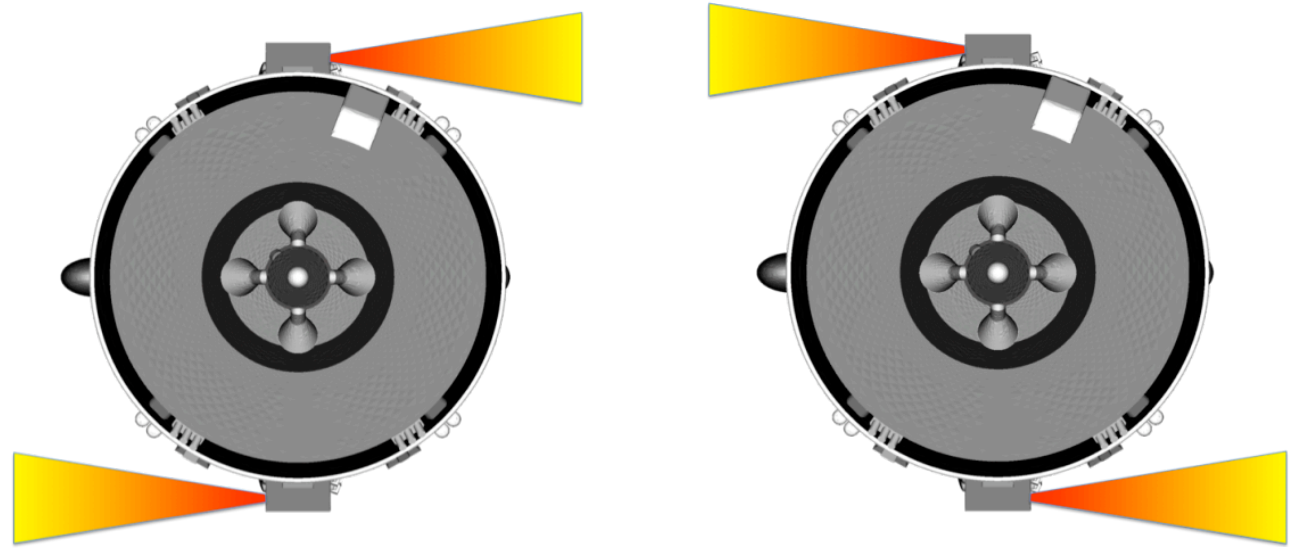

Figure 6. Pictorial representation of the RoCS jet firing for positive and negative rolling moments. 
The situation for powered RoCS is illustrated in figure 7. The left figure shows the computational mesh on a plane cutting through the center of the RoCS nozzles and housing, where the nozzles have been truncated downstream of the throat but upstream of the nozzle exit plane. Clustering of grid points out from the nozzle and into the free stream was used to provide adequate grid resolution to support plume development and interaction with the free stream. For each free stream condition, the procedure developed by Abdol-Hamid et al. was used to compute an appropriate flow field distribution to be applied as the boundary condition at the inflow plane. An illustration of a RoCS plume and resulting flow field produced using this boundary condition at Mach 1.6 is shown in the right side of figure 7.

Note that the motors for inducing a negative rolling moment $(\mathrm{CCW})$ are located at the front of the housing, while the motors for inducing a positive rolling moment $(\mathrm{CW})$ are placed at the back of the housing. This placement of the RoCS thruster leads to asymmetric jet interaction effects that depend upon which set of jets is firing.

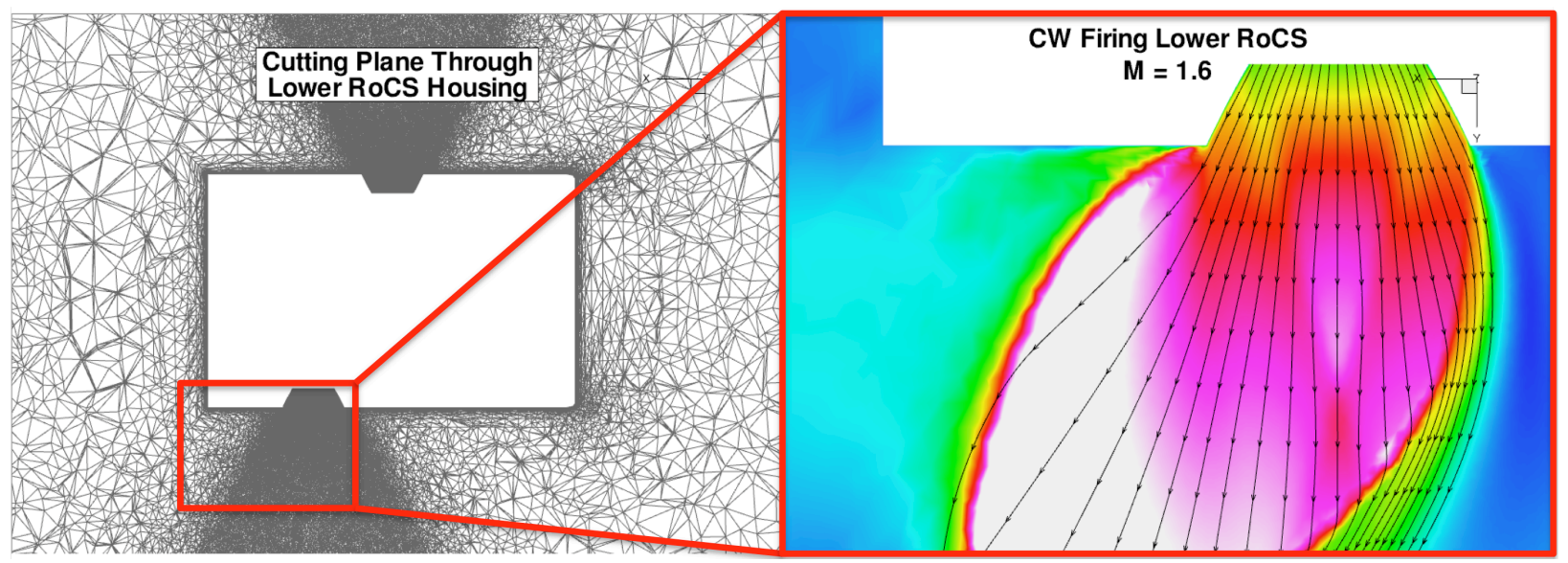

Figure 7. Pictorial representation of the truncated RoCS nozzles (left) and application of the inflow boundary condition for a CW firing of the RoCS thruster at Mach 1.6.

The CFD flow solver USM3D was used to analyze the plume-induced interactions of the RoCS jets on the environment for the Ares I-X FTV. Analyses were conducted at Mach numbers 0.3, 0.5, 0.9, 1.2, 1.6, 2.0, 3.0, and 4.5 at total angles of attack of $0^{\circ}$ and $4^{\circ}$ (with additional cases at $\alpha_{\mathrm{T}}=10^{\circ}$ at Mach 0.3 and 0.5 and at $\alpha_{\mathrm{T}}=20^{\circ}$ at Mach $=0.3$ ) and roll angles from $0^{\circ}$ to $360^{\circ}$ with increments of $30^{\circ}$. All analyses were conducted at flight Reynolds number conditions. Simulations were run with all of the RoCS jets idle, the two jets for positive roll control ON, and the two jets for negative roll control ON. Comparisons to the flight test reconstructed rolling moment will be discussed in a later section of the paper.

\section{J. BDM Jet Interaction Database}

The booster decelerator motors (BDMs) used on the Ares I-X FTV were comprised of a modified version of Allient Techsystems Inc. (ATK) booster separation motors (BSMs) that jettison the Space Shuttle reusable solid rocket motors (RSRMs) away from the Shuttle orbiter and external tank. While the performance parameters of the BDMs were supplied by ATK, plume-induced interactions of the BDM jets on the environment of the full stack were assessed with CFD.

Analyses of the BDM jet effects were conducted with the USM3D flow solver at a Mach number of 4.5, angles of attack of $0^{\circ}$ and $3^{\circ}$, and roll angles from $0^{\circ}$ to $360^{\circ}$ with increments of $30^{\circ}$. All analyses were conducted at flight Reynolds numbers. Simulations were run with the BDM jets idle and all 8 jets on. Additional cases were run at Mach 4.5, total angle of attack of $0^{\circ}$ and roll angle of $0^{\circ}$ with one jet on, four jets on one side of the vehicle turned on, and seven jets on. With the force and moment coefficients provided at the gimbal of the FS, the jet-interaction values were found by subtracting the idle coefficient values from the firing values (without including the thrust of the BDMs themselves).

Mach contours for all 8 BDMs firing are shown in figure 8 . The left figure shows a cross section along the lateral symmetry plane. Red contours forward of the aft skirt indicate that the high-speed flow of the BDM plumes extend upstream for more than a quarter of the length of the FS. The blue contours indicate that the blockage effect of the plume was substantial, generating low speed flow along the forward section of the FS with flow separation initiated slightly upstream of the conjunction of the interstage with the frustum. In hindsight, the elimination of the RoCS housings, dummy BTMs, and the protuberances immediately in front of the interstage, to decrease the size of 
the grid, was not a good decision; the wakes off of those protuberances may have enough influence to pull the initiation of separation even further upstream on the interstage. The right half of figure 8 shows Mach contours along a cylindrical surface at a constant offset height above the FS and cuts through the centerline of the BDM nozzles. The complex shock patterns are indicative of the influence of the FS rings on plume behavior.

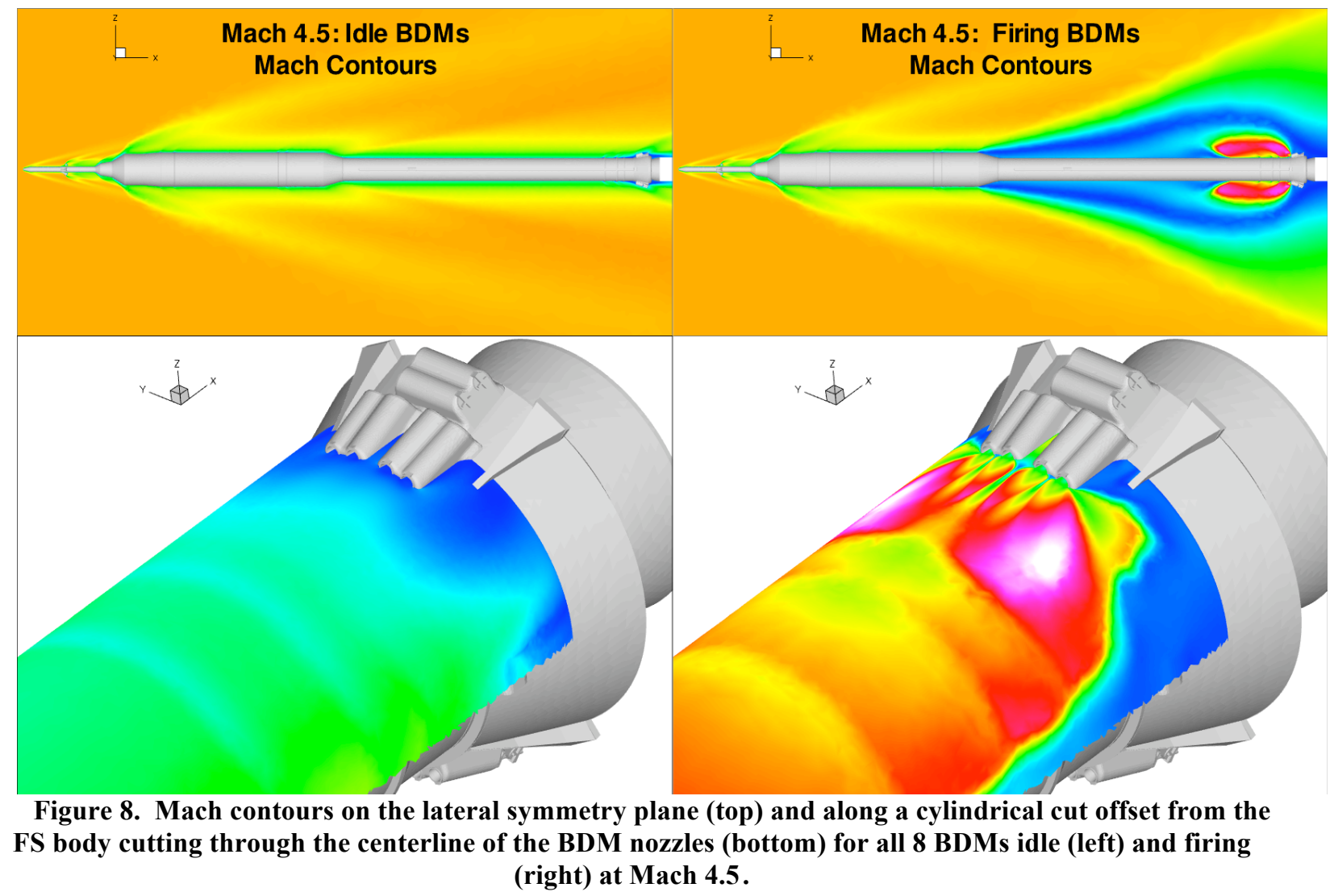

The effect of the variation in atmospheric conditions between nominal and off-nominal trajectories on the BDM Jet Interactions was expected to be significant; a simple equation to correct for this effect was included in this database. Because of the jet interaction variations with atmospheric conditions, this database includes a thrust coefficient term that was based on the reference values for nominal thrust, nominal dynamic pressure, and reference area of the vehicle.

\section{K. BTM Jet Interaction Database}

The booster tumbling motors (BTMs) used on the Ares I-X FTV were comprised of a modified version of ATK BSMs. The requirement for BTM simulations was substantially less than that for the other engine simulations, since the point in flight at which the BTMs were fired was after the FS had already separated from the USS, while placement of the BTMs on the aft skirt, in conjunction with a Mach 4.5 free stream flow, ensured that the BTM jet effects would be localized far downstream of the separation plane. Note that a similar situation does not hold for the Ares I CLV, where the separation plane is at the conjunction of the US and interstage, while the BTMs are located on the frustum.

Analyses of BTM jet effects were conducted using the USM3D flow solver at a Mach number of 4.5 with the FS separated from the USS. As shown in figure 9, the simulations were conducted at a single separation distance with FS incidence angle to the USS at $-6^{\circ}, 0^{\circ}$, and $6^{\circ}$, thereby covering the full range of expected deviations in incidence angle. All analyses were conducted at flight Reynolds numbers. Jet effect increments were determined by running the simulations with the BTM jets idle, then with all four jets turned on. The incremental coefficients due to BTM jet interactions do not include the side force coefficient contribution from BTM thrust. The geometry used for the CFD predictions was the AIX FTV OML v2.01. The BTM jet interaction incremental coefficients were provided in the body axis coordinate system. 
A different grid was generated for each orientation of the FS with respect to the USS. Each grid contained roughly $49.8 \mathrm{M}$ cells and used a near wall spacing of 0.001 inches (this corresponds to a y+ value of 0.2 or less). The internal geometry of the four nozzles located within the two BTM housings was modeled in the same manner as for the other powered simulations, in which the nozzle is truncated downstream of the nozzle throat and upstream of the nozzle exit plane. Taking the BTM jet flow profile at the exit plane and applying an ideal gas analysis to determine the corresponding conditions at the truncated plane generated appropriate boundary conditions at the truncated nozzle plane. To capture the complex interaction of the BTM jets with the free stream flow, the grid near each BTM nozzle was refined with approximately $2 \mathrm{M}$ more cells than used in the full protuberance grids.

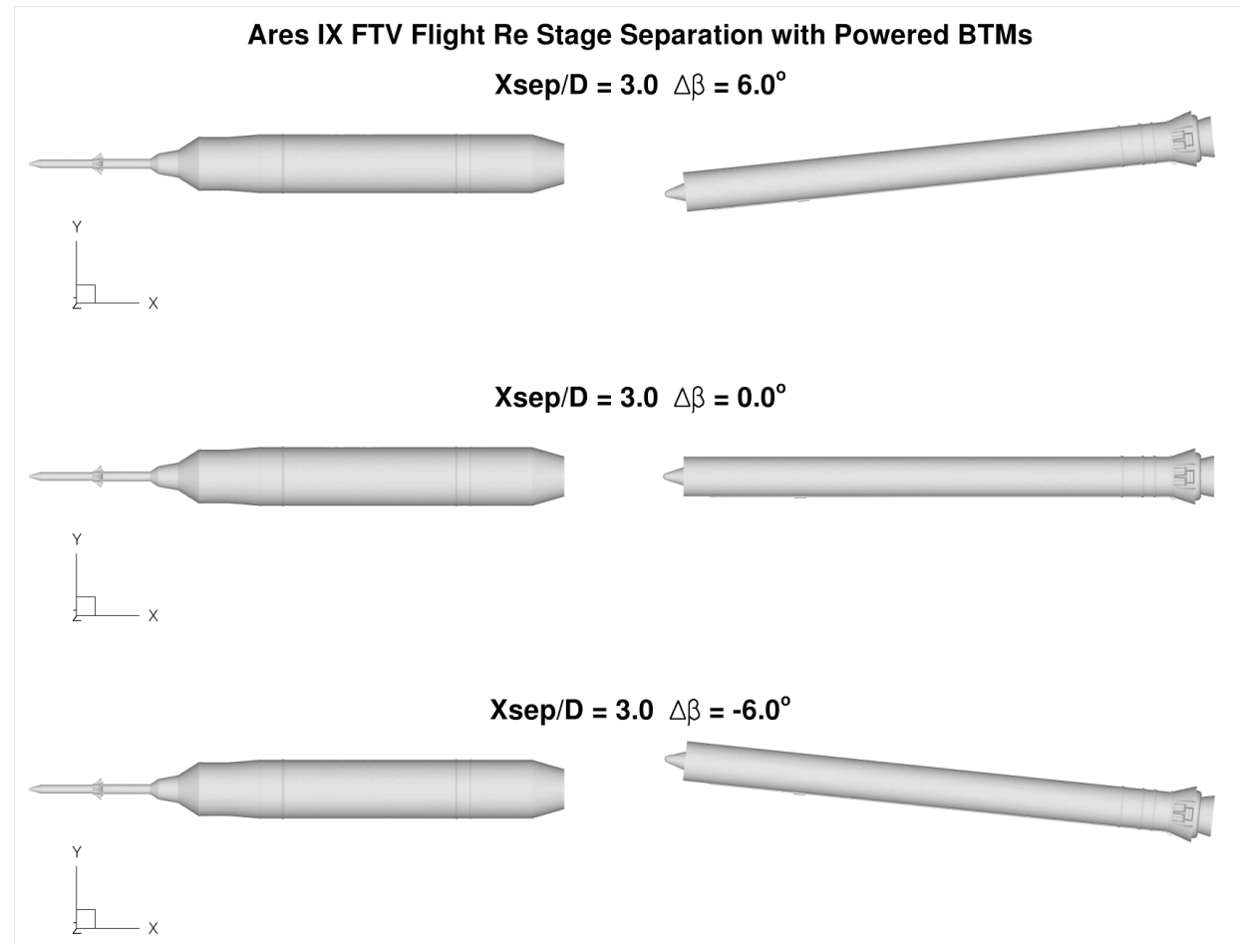

Figure 9. Orientation of the FS relative to the USS at the commencement of BTM ignition.

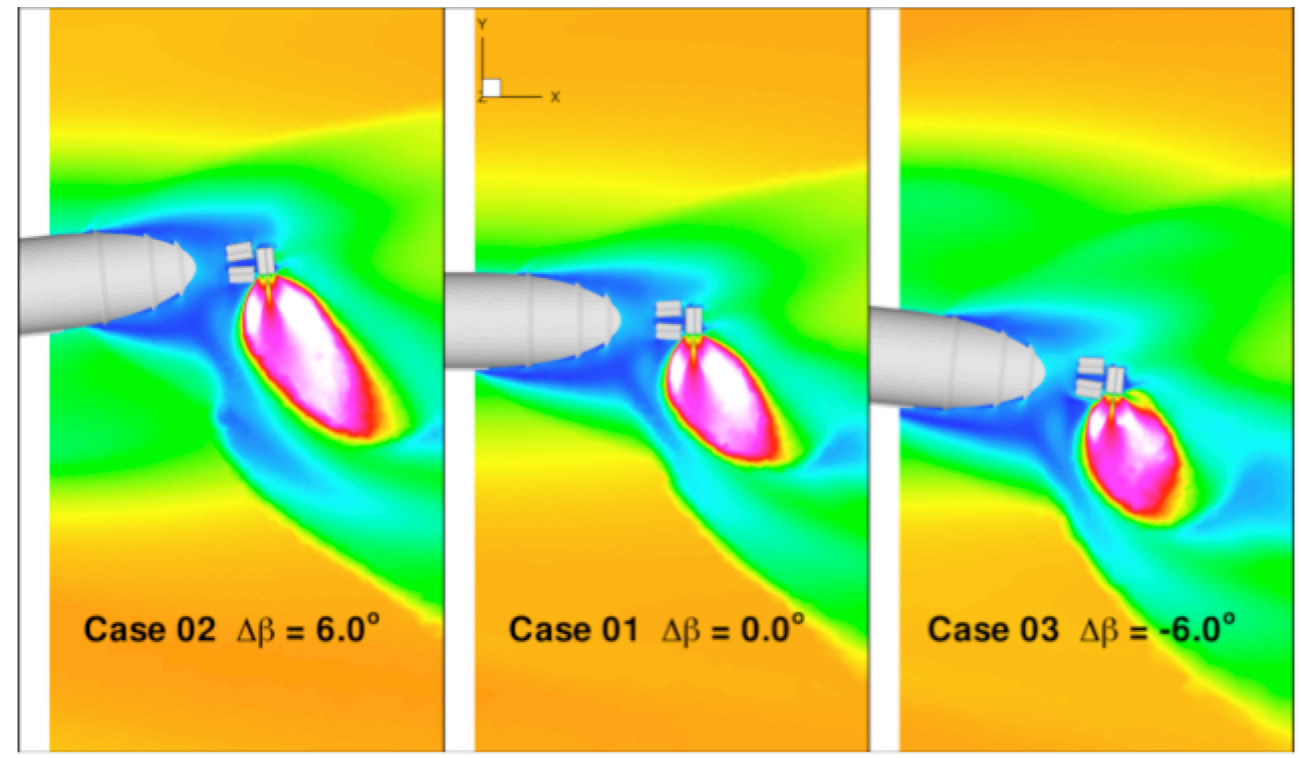

Figure 10. Mach contours along a plane that cuts through the center of the BTM nozzles at three incidence angles of the FS with the USS. Flow direction is from left to right at Mach 4.5. 
Mach number contours in the vicinity of the upper BTMs are shown in figure 10 for the three orientations of the FS relative to the USS, with the flow direction from left to right. The Mach contour plane cuts through the center of the BTM nozzles, with the angle of the plane from horizontal matching the angle of the apex of the aft skirt from horizontal. The gray surfaces depict the first stage OML upstream of the aft skirt and the surfaces of the upper BTM and upper BDMs that lie above the cutting plane. Note that the lower BTMs fire in the same direction as the upper BTMs to induce tumbling without increasing rolling moment. The Mach contours indicate that expansion of the down stream jet was significantly greater than that of the upstream jet, as it operated in a region of lower back pressure due to the influence of the upstream jet. Large variations in plume extent occur with changes in the incidence angle of the FS to the free stream flow, with plume extent decreasing as the incidence angle decreases.

\section{Post Flight Computations}

As flight test data became available, post-flight computations were run for the best-estimated trajectories (BET) as they were supplied to the aerodynamics team. A total of four BETs were released (i.e., BET1, BET2, BET3, and BET4 or the final BET), each of which was run to a varying degree. These runs were conducted using the SA turbulence model on the finest grid available, which was developed for the Full Protuberance configuration.

As it became apparent that there were significant discrepancies between predicted and flight performance of the FTV at conditions for which the RoCS were firing, additional simulations were conducted using the Powered RoCS configuration. This investigation included both grid refinement studies and the comparison of results using Menter's Shear-Stress Transport (SST) turbulence model to those from the SA model used in generating the results incorporated into the ascent and RoCS JI databases.

Most of the study into the deficiency of the RoCS JI database was completed by the time that the "As-Built" configuration became available. Consequently, lessons learned from that study were incorporated into generating the "As-Built" grid. The "As-Built" grid had all of the configuration features of the Full Protuberance and Powered RoCS grids, plus some of the finer features that were not modeled on the preflight configurations. Not only are the RoCS nozzles modeled to provide RoCS JI increments, but also the FS nozzle was modeled to provide power-on base force assessments. The resolution on the "As-Built" grid was also refined in areas that were found to be the largest contributors to the RoCS JI effect on rolling moment, particularly around the RoCS housings. As a result, the "As-Built" grid embodied twice as many volume cells as the Full Protuberance grid.

During the investigation of the discrepancy between flight data and database results for the RoCS JI effect, it was found that the SST model results showed a lower interference effect on rolling moment coefficient than the SA results, and agreed more closely with the flight results. Consequently, the run matrix for the "As-Built" grid included both models for all conditions (though the SST model had yet to be run at all of the conditions in the matrix). Most of the computational runs were made with the FS motor firing at a thrust level that closely matched the estimated flight value at each specified flight condition. All of the conditions were run with the RoCS motors idle, and cases with the RoCS motors firing were only run at conditions that cover the firing sequence during flight.

The RoCS JI effect on rolling moment coefficient for the SA and SST runs is shown in figure 11. The SA curve includes the data for both the powered RoCS cases and the idle RoCS cases (those conditions where the RoCS were not fired). Hence, spikes in the SA curve indicate conditions where the RoCS were fired. For $\mathrm{M}<0.4$, the RoCS was fired to induce a positive rolling moment; the fact that the RoCS JI values were negative indicate that jet interference effects countered the commanded roll authority. Between Mach 0.6 and 0.92 the RoCS was fired to induce a negative rolling moment, and again the RoCS JI effect on rolling moment was in the opposite direction. Between Mach 1 and Mach 1.5 the RoCS was fired to induce a positive rolling moment, and in these cases the CFD results between Mach 1 and 1.1 indicated a negative RoCS JI effect, but the values at Mach 1.42 were positive, reinforcing the commanded roll authority. Above Mach 2, the RoCS were fired to induce a negative rolling moment. 




Figure 11. RoCS JI effect on rolling moment for SA vs. SST .

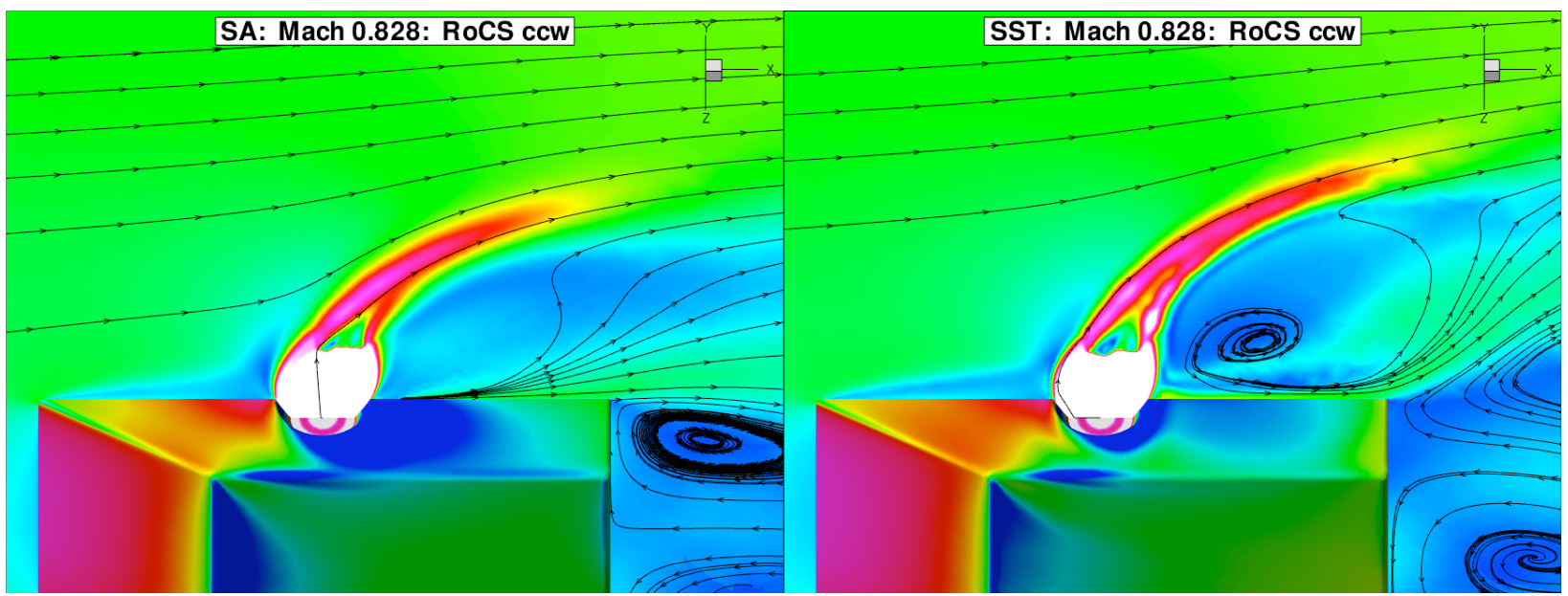

Figure 12. Pressure coefficient contours on the upper RoCS housing and Mach contours on a cutting plane through the housing for SA and SST at Mach 0.828 .

For all but the Mach 1.42 case, the magnitude of the SST RoCS JI value was lower than the corresponding SA value, thereby indicating that the RoCS JI penalty on rolling moment was less severe for the SST model than for SA. At Mach 1.42, both the SA and SST runs indicated a RoCS JI benefit, with SST providing a slightly larger benefit. At Mach 3.043, the SST result suggested that the RoCS JI provided a small penalty, while the SA result suggested an even smaller benefit. The largest inconsistency in the trends occurred for the SST result at Mach 0.888, where the magnitude of the RoCS JI value was significantly smaller than for the other three cases in the Mach 0.82 to 0.92 range; the result was attributed to difficulties in obtaining a converged solution at this condition.

Plots of the rolling moment coefficients for all individual components were examined to identify the largest contributors to the rolling moment coefficient and to ascertain where the differences between the SA and SST results were generated. While the RoCS housings and the protuberances on the aft skirt were the largest contributors to rolling moment, differences between the SA and SST results were primarily due to the RoCS housing. The cause of those differences can be seen in figure 12, where pressure distributions on the upper RoCS housing and Mach contours on a cutting plane through the upper RoCS housing are shown for the SA and SST solutions at Mach 0.828. 
The SST model preserved the jet plume wake better than the SA model. The resultant increase in the extent of cross flow yields a somewhat higher pressure distribution on the front of the housing and less suction on the back of the housing, with both increments on rolling moment acting in the direction of the commanded roll.

\section{Comparison of Flight, Database, and CFD Results}

The Ares I-X FTV was a heavily instrumented launch vehicle. The FTV had 243 unsteady pressure (Kulite) gauges installed on the surface of the vehicle. In addition, the vehicle had numerous strain gauges, accelerometers, thermocouples, and other instruments to measure the flow characteristics, determine the vehicle state and location, and control the vehicle during flight.

The results for the post flight analyses are presented in 2 parts: (1) force and moment comparisons between flight measurements, aerodynamic database predictions, and CFD results; and (2) surface pressure comparisons between USM3D results and FTV DFI flight data.

\section{A. Force and Moment Comparisons}

The flight reconstructed rolling moment characteristics of the FTV are compared to the flight control model utilizing the MLOAHA database and the RoCS JI database, as well as to post flight CFD results. Comparisons of the flight reconstructed axial force coefficient are made to the MLOAHA database and CFD results. Comparisons for the normal force, side force, pitching moment, and yawing moment are absent, as it was not possible to reconstruct these coefficients from the flight data. All of the results are taken at specific points along the final best estimated trajectory (BET) provided by the Ares I-X trajectory and GN\&C integrated design and analysis teams.

Figure 13 shows the rolling moment from the flight reconstructed values (red curve) and the GN\&C model utilizing the preflight RoCS jet interaction database (blue curve). Spikes in the amplitude indicate conditions at which the RoCS motors were firing. For conditions at which the RoCS motors were idle, significant differences exist between the database and the reconstructed rolling moment values, particularly over the Mach number range from 1.0 to 3.0. These differences could be due to the fact that the rolling moment balance reading during the wind tunnel tests of the A101 configuration were on the order of the balance accuracy.

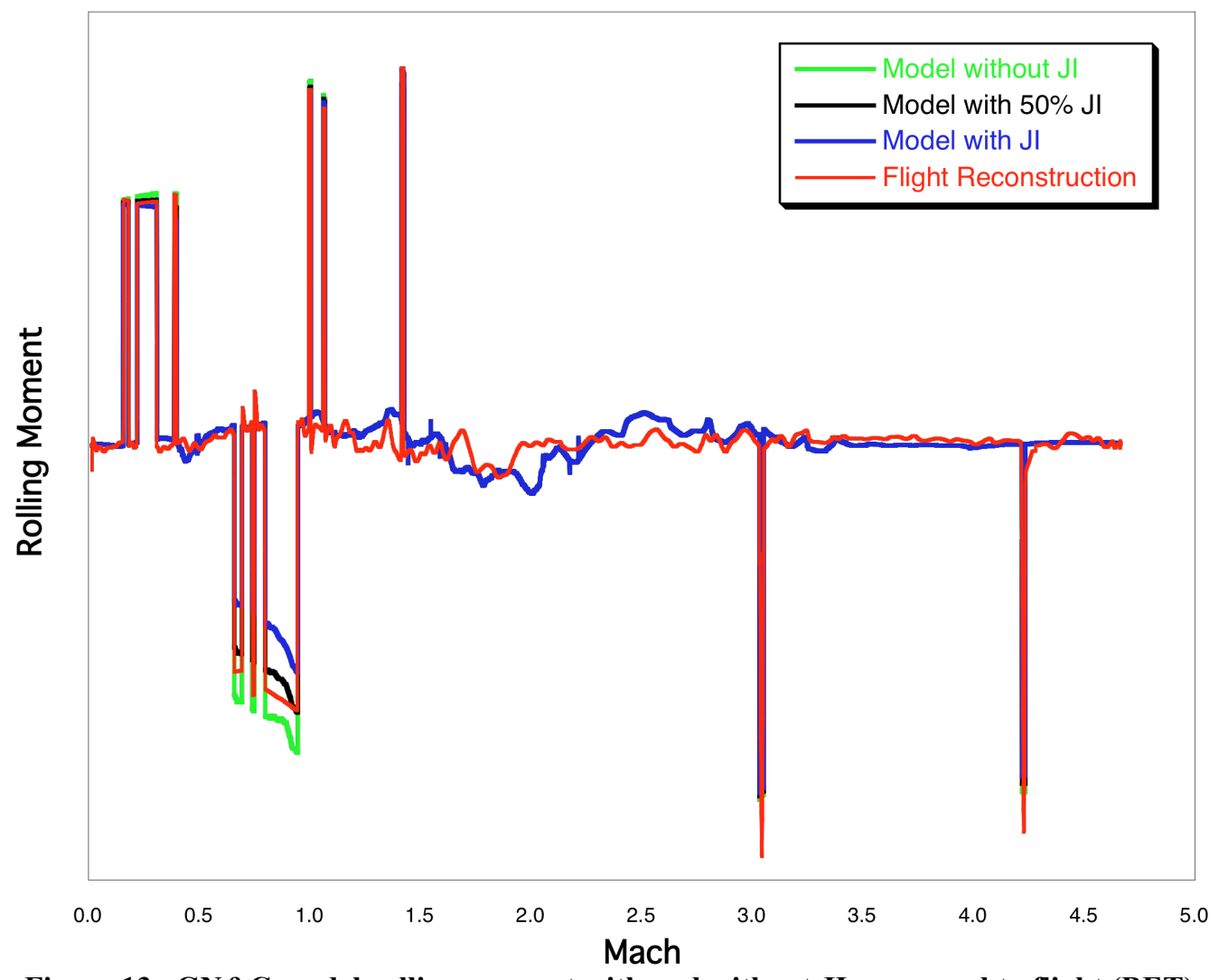

Figure 13. GN\&C model rolling moment with and without JI compared to flight (BET). 
For conditions at which the RoCS motors were fired to produce a positive rolling moment, which includes the ranges below Mach 0.5 and between Mach 1.0 and 1.5, the flight reconstructed and database rolling moment values are fairly comparable. However, for conditions at which the RoCS motors were fired to produce a negative rolling moment, which includes the ranges from Mach 0.65 to 0.95 and above Mach 3.0, the rolling moment is underpredicted to a significant extent.

The final two curves in Figure 13 show what the GN\&C model would predict if no RoCS jet interaction increment was included (green curve), and if only $50 \%$ of the jet interaction was used (black curve). At the transonic conditions, it is evident that the RoCS JI database over-predicts the adverse jet interactions for the negative rolling moment firing cases by 50 to 60 percent. At Mach 3.04 and 4.23, the reconstructed values are higher than the rolling moment that would be produced by thrust from the RoCS motors in isolation, as measured in ground tests. Thus, the jet interacting with the FTV induces an additional beneficial rolling moment increment that was not predicted by the CFD methods.

Figure 14 compares the flight reconstructed rolling moment to the database values at the final BET conditions and to post-flight CFD results. The post-flight CFD simulations differ significantly from the pre-flight simulations, as the grid used in the post-flight simulations was based on the updated "As-Built" OML and grid refinements were implemented around the protuberances that have the largest effect on rolling moment. In addition, computations were conducted with both the SA and the SST turbulence models, whereas the SA model was used in pre-flight simulations for generating the RoCS JI database

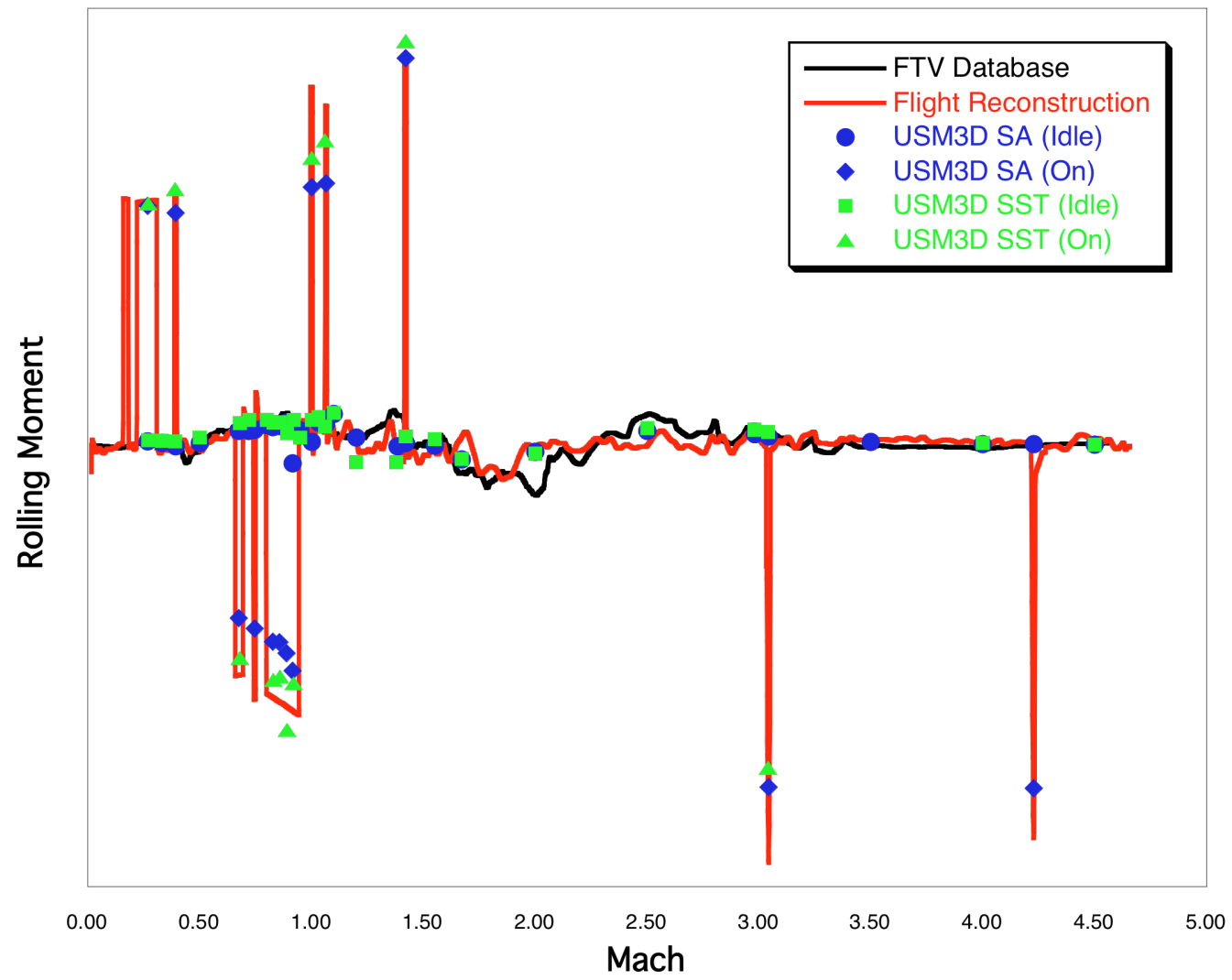

Figure 14. GN\&C model rolling moment with and without JI compared to flight (BET).

For conditions at which the RoCS motors were idle, the post flight CFD results are in better agreement with the reconstructed flight data than the database values. At subsonic conditions near Mach 0.27, both turbulence models accurately predict the jet interactions due to a positive firing of the RoCS. At a slightly higher Mach number of 0.39 , the SST turbulence model captures the JI of the positive firing RoCS more closely than the SA turbulence model. This trend continues for negative firing RoCS for Mach numbers of 0.67 to 0.91 and for positive firing RoCS at Mach 1.00, 1.07, and 1.42. However, at Mach 1.00 and 1.07, both turbulence model results over predict the jet interactions (reducing the net rolling moment) and thus, do not match the flight reconstructed values. At Mach 1.42, the SA turbulence model appears to do better at predicting the JI effects while the SST model slightly over predicts the JI effects, with both models predicting that the RoCS JI reinforces the commanded roll authority at 
this condition. As mentioned previously in the discussion of the data in figure 13, the flight reconstruction rolling moment values are higher than the RoCS thrust would predict at the high supersonic Mach numbers. The CFD solutions for both turbulence models suggest that there is very little JI occurring at these supersonic conditions. However, the flight reconstruction rolling moment values would suggest that an increase in effectiveness of the RoCS is occurring at these conditions, implying that a reinforcing RoCS JI is present.

Figure 15 is a plot of the axial force coefficient as a function of Mach number. The aerodynamic database values are shown as the black curve. Three sets of CFD results from USM3D are shown; blue circles are for the SA turbulence model on the full protuberance OML, red squares are for the SA turbulence model on the "As-Built" OML, and green diamonds are for the SST turbulence model on the "As-Built" OML. The CFD results are seen to be lower than the database values for Mach numbers below Mach 3.0. The discrepancy between the CFD and database is primarily due to the fact that CFD typically under-predicts the $\mathrm{C}_{\mathrm{AF}}$ values seen in the wind tunnel and at flight Reynolds numbers.

The solid red curve is the reconstructed axial force coefficient from flight. The flight data is based on values for thrust and mass for day of launch conditions, as provided by the First Stage Integrated Product Team (FS-IPT). It also contains the power-on base force values derived from DFI during the flight of the FTV. The gray shaded area encompasses the dispersion bounds specified in the FTV MLOAHA aerodynamic database. The orange shaded area represents a thrust error of $+1 \%$ and $-1 \%$, respectively. Although the FS-IPT provided no dispersions or error bounds for their thrust estimates during the flight, it was felt that a maximum error value of $1 \%$ in the data was possible. Most of the transonic CFD values fall outside of the $1 \%$ thrust error shaded area, but still fall inside the MLOAHA database dispersion bounds.

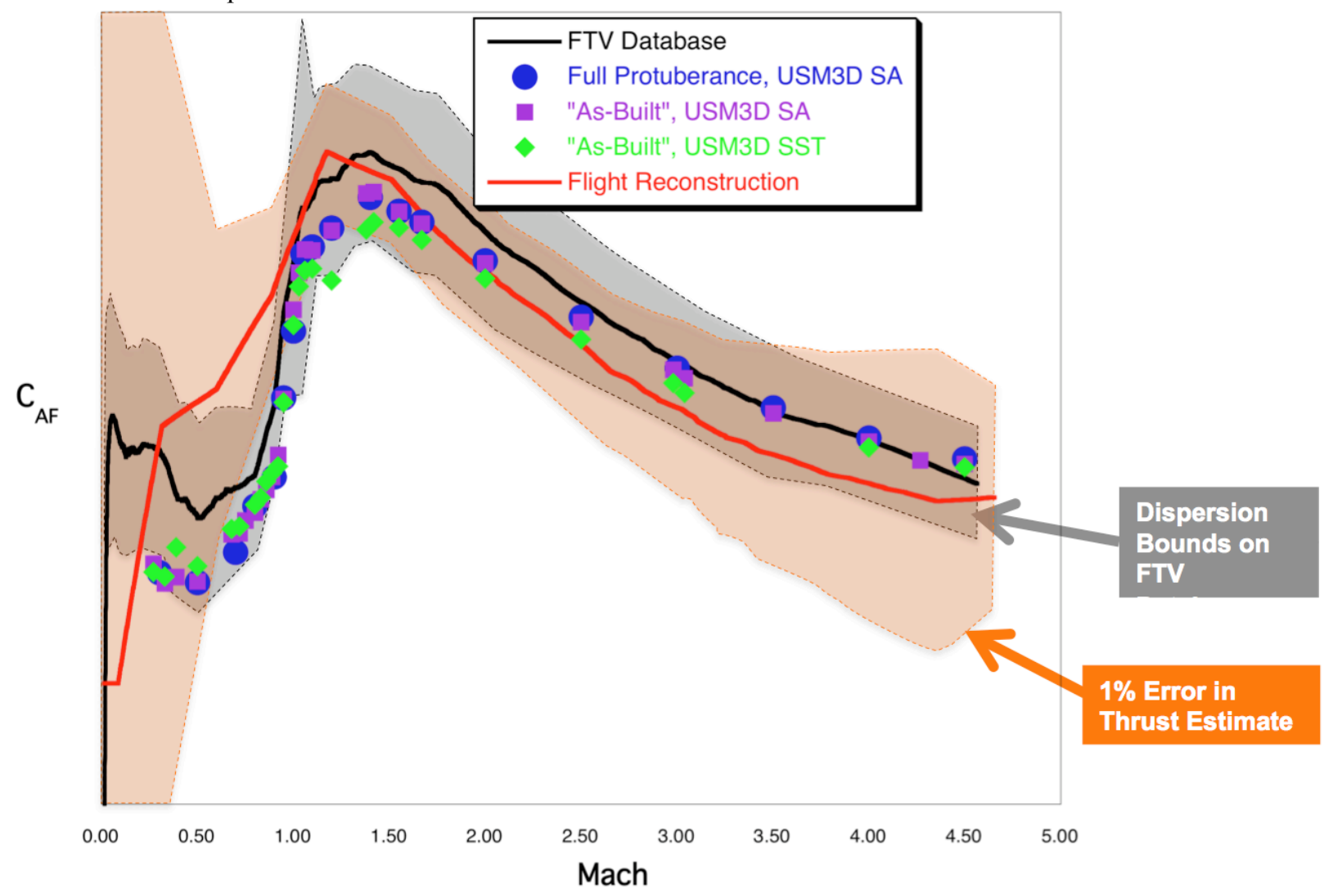

Figure 15. Axial force coefficient comparison between aerodynamic database, flight and CFD.

\section{B. Surface Pressure Comparisons}

During the preparation for the flight test of the Ares I-X FTV, a considerable amount of effort was placed on determining the number and locations of DFI to be included on the vehicle. The extent of calibration of the DFI was also discussed prior to installation and continued until the flight of the vehicle. As reported in the DFI data book (AI1-SYS-DFI), there were a total of 716 sensors installed on the vehicle. The FTV had 243 unsteady pressure 
(Kulite) gauges installed on the surface of the vehicle. This section of the report will discuss how well the USM3D Navier-Stokes solver results compared to the flight surface pressure measurements.

Figure 16 shows surface pressure coefficient values along 4 azimuthal angles on the FTV at Mach 0.8 , which is a condition for which the RoCS motors were idle. The horizontal axis encompasses the entire length of the FTV, while the vertical axis for the pressure coefficient is constructed with positive values at the bottom of the scale and negative values at the top. Flight data is shown as the blue symbols, while USM3D values for simulations at wind tunnel and flight Reynolds number conditions are shown in black and red, respectively; the gray shaded surface represents the profile of the vehicle but is not to scale. The wind tunnel Reynolds number simulation was conducted on the full protuberance grid for the pre-flight OML, whereas the flight Reynolds number simulation was conducted on the post-flight grid that uses the "As-Built" OML. Due to the compressed scale of the horizontal axis, the differences between the two simulations and the flight data are difficult to discern. Nonetheless, it is evident that differences between the wind tunnel and flight Reynolds number predictions are not large at this condition, while the flight DFI data are predicted reasonably well with either solution.

Figure 17 shows the same stations as figure 16, but compares the SA (black) and SST (red) turbulence model results at Mach 0.83 for flight Reynolds number conditions; this is a condition at which the RoCS motors were firing to produce a negative $(\mathrm{CCW})$ rolling moment. Both simulations were conducted on the "As-Built" grid. Overall, either turbulence model does reasonably well at predicting the surface pressures on the vehicle. However, there are subtle differences between the two solutions that are detailed in the next 3 figures, starting at the top of the vehicle and working down to the aft skirt.

SA: RoCS idle: FS Motor idle

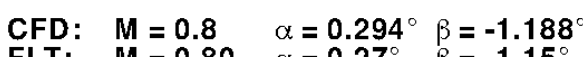

FLT: $\quad M=0.80 \quad \alpha=0.27^{\circ} \quad \beta=-1.15^{\circ}$


Figure 16. Surface pressure coefficient comparison between flight and CFD (USM3D with SA turbulence model at wind tunnel and flight Reynolds number conditions), Mach 0.8 . 

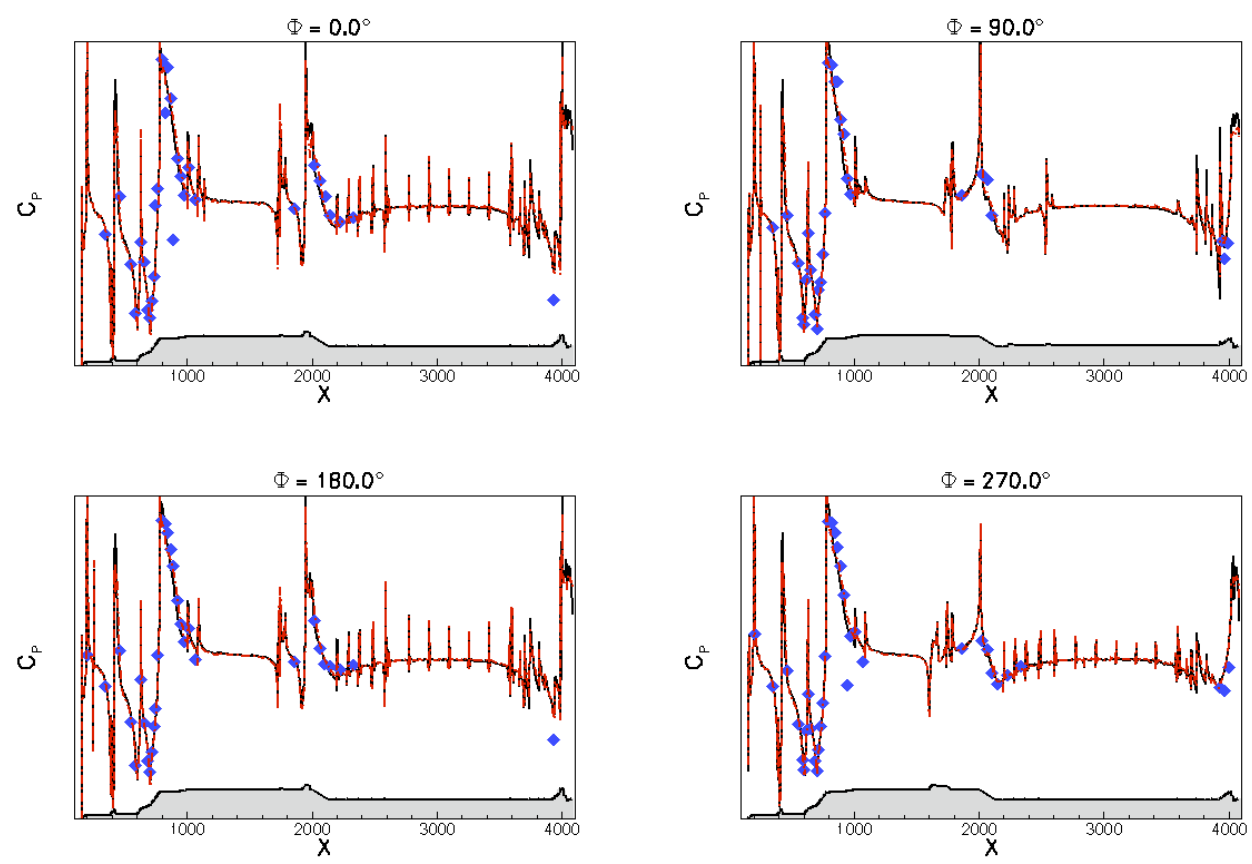

Figure 17. Surface pressure coefficient comparison between flight and CFD (USM3D with SA and SST turbulence models at flight Reynolds number conditions), Mach 0.83 .

Figure 18 shows a comparison of the flight DFI with the USM3D SA and SST results at Mach 0.83 over the LAS tower and crew module (CM/LAS) and the upper portion of the USS, which includes the service module (SM) and spacecraft adapter (SA). It is evident that either turbulence model could be used to predict the surface pressure over the CM/LAS. The flight surface pressures on the SM and SA are not predicted as accurately by either turbulence model. This is due to the rapidly changing flow characteristics at these flight conditions. The flow tends to expand rapidly at the shoulder of the crew module and at these transonic conditions can lead to a separated flow region (as seen in wind tunnel tests and previous CFD studies). In addition, the flight pressure values are an average of the values measured over a 0.5 second time frame. Thus, the conditions measured and predicted with the CFD code could be slightly different. The difference between CFD results and flight measurements show that this region on the vehicle could be experiencing a larger or smaller region of separated flow at any particular instant in time. 

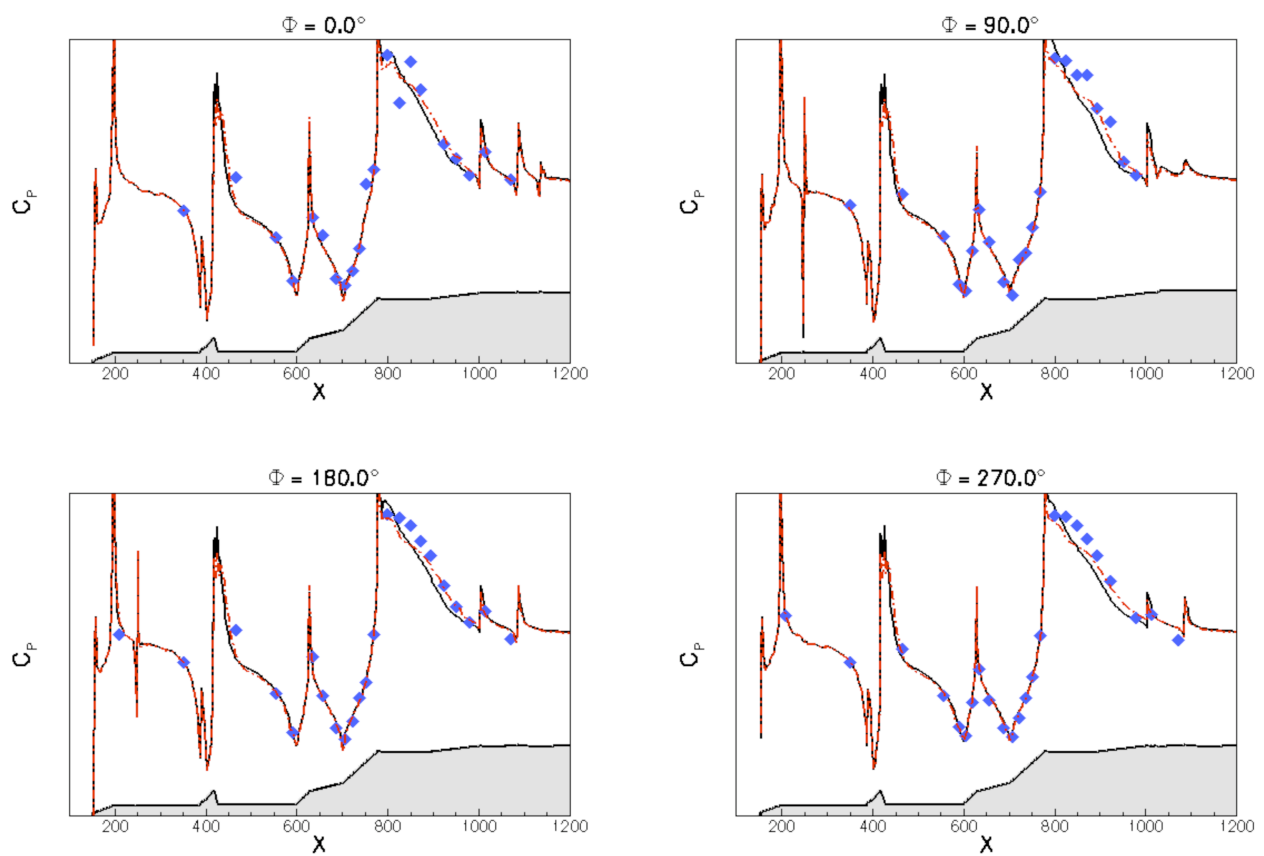

Figure 18. Surface pressure coefficient comparison between flight and CFD (USM3D with SA and SST turbulence models at flight Reynolds number conditions), Mach 0.83, top of vehicle.

Figure 19 shows a comparison of the surface pressure coefficients from flight and the USM3D SST results with RoCS idle versus RoCS firing in the CCW direction at Mach 0.83. This is a condition at which the RoCS was fired during the flight, therefore, it is expected that running the CFD with the RoCS firing would provide a better match to the flight data than having the RoCS idle. The figure shows that at $\phi=0^{\circ}$ and $180^{\circ}$, the USM3D results with the RoCS firing matches the flight surface pressures better than the results with the RoCS idle. The $\phi=90^{\circ}$ and $270^{\circ}$ plots show very little difference between the 2 CFD results, as the interaction of the RoCS jet plumes with the free stream has little effect on either region of the vehicle.

Figure 20 focuses in on the aft end of the vehicle, comparing results from the SA and SST turbulence models (again at Mach 0.83 with RoCS firing in the CCW direction). For this particular case, the SA turbulence model has slightly higher pressures than the SST model. However, neither method matches the flight values, for which the pressure is consistently higher. It is surmised that a large portion of the mismatch between prediction and flight reconstruction of the axial force, as seen in figure 15, is due to inaccurate modeling of the flow in the region of the aft skirt. Both turbulence models appear to predict greater losses in the boundary layer, the consequence being that the pressure does not react or recover as quickly when it encounters the large stiffener rings at the aft end of the FS. Conversely, the DFI indicate that the flow is still able to react and recover quickly during these encounters, with the higher pressures on the front faces of the rings producing more drag. Hence, it is assumed that this is where a large portion of the mismatch in axial force is occurring. 

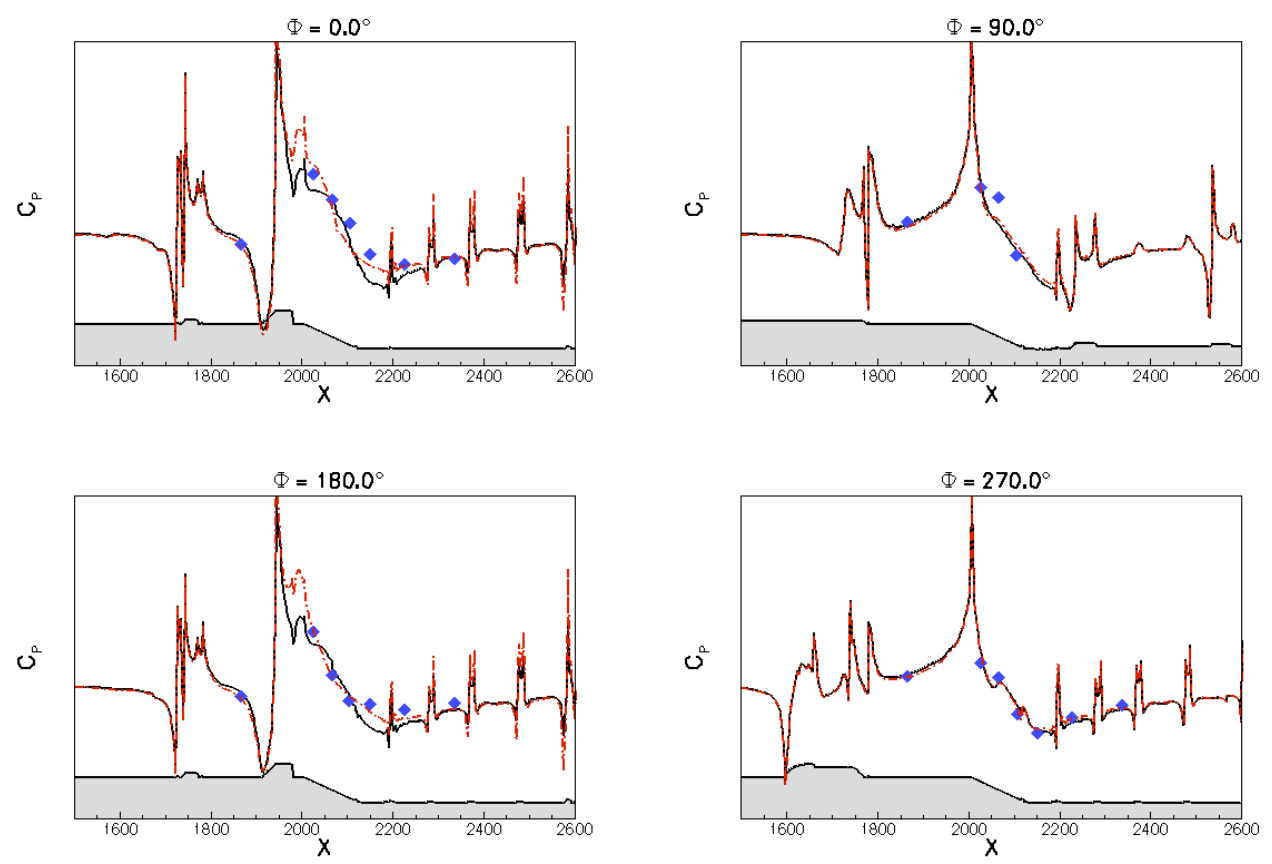

Figure 19. Surface pressure coefficient comparison between flight and CFD (USM3D with SST turbulence model at flight Reynolds number conditions, idle and firing RoCS), Mach 0.83, IS and frustum.
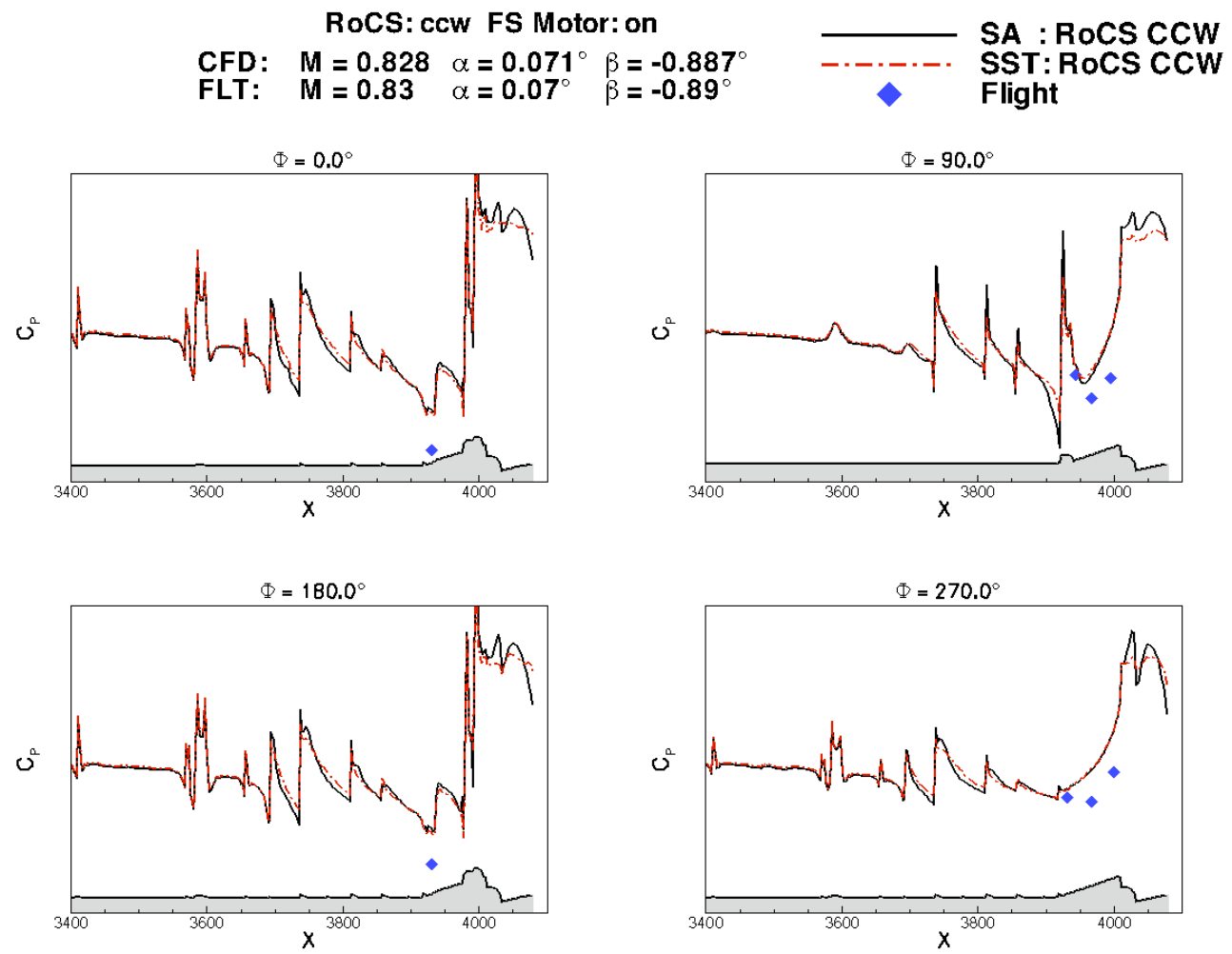

Figure 20. Surface pressure coefficient comparison between flight and CFD (USM3D with SA and SST turbulence models at flight Reynolds number conditions), Mach 0.83, FS and aft skirt. 


\section{Conclusion}

The aerodynamic databases for the Ares I-X FTV were constructed by merging results from several experimental studies on similarly shaped launch vehicle configurations with the results from a limited set of CFD simulations on a number of versions of the Ares I-X FTV OML. CFD studies were conducted at both wind tunnel and flight conditions. While performance parameters for the main engine, RoCS, BDM, and BTM engines were provided by the equipment manufacturers, all jet effect interactions between the free stream flow and jet plumes were accounted for as increments predicted from CFD studies at flight conditions. In order to bound potential deviations from the predicted performance, additional increments were added to the databases to incorporate uncertainty estimates; the magnitude of those increments frequently exceeded the range of variations present in the computational results.

Despite the large magnitude of uncertainty rolled into the aerodynamic databases, the flight of the Ares I-X FTV on October 28, 2009 was nominal, other than an issue with deployment of the FS parachutes. Post-flight analysis of the flight data revealed that deviations from the predicted performance were well within expectations, with the exception of the vehicle response to firing of the RoCS. However, the trajectory of the vehicle strayed so little from the nominal trajectory that there is no way to assess the accuracy of the databases outside a tightly constrained band about the nominal trajectory.

\section{References}

${ }^{1}$ Pandya, Mohagna J.; Parikh, Paresh; and Frink, Neal T.: “USM3Dns User's Online Manual,” [online database], URL: http://tetruss.larc.nasa.gov/usm3d_v52/usm3d_52_man.html [cited August 2000].

${ }^{2}$ Frink, N. T., "Tetrahedral Unstructured Navier-Stokes Method for Turbulent Flows, "AIAA Journal, Vol. 36, No. 11, November 1998, pp. 1975-1982.

${ }^{3}$ Mean Forces, Pressures and Moments for Circular Cylindrical Structures: Single Cylinder with Two-Dimensional Flow. ESDU 80025, June 1986.

${ }^{4}$ Bonner, E.; Clever, E.; and Dunn, K.: Aerodynamic Preliminary Analysis System II, Part I - Theory. NASA CR 182076, April 1991

${ }^{5}$ Sova, G. and Divan, P.: Aerodynamic Preliminary Analysis System II, Part II-User's Manual. NASA CR 182077, April 1991.

${ }^{6}$ Deere, K. A., Pao, S. P., and Abdol-Hamid, K. A.: A Computational Investigation of the Roll Control System Jet Interactions on Rolling Moment of the Simplified Ares I-X Configuration, NASA/TP-2010-000000 (in print), June 2010.

${ }^{7}$ Abol-Hamid, Khaled S.; Ghaffari, Farhad; Pao, Paul S.; Deere, Karen A.; and Parlette, Edward B.: Computed Turbulent Ascent Aerodynamic Data Analysis for the Proposed Ares-I ADAC2A Configuration. Ares-AD-TA-0005, July 2007 